\title{
Calibration of the SPEARpesticides Bioindicator for Cost-effective Pesticide Monitoring in East African Streams
}

\section{Akbar A Ganatra}

International Centre for Insect Physiology and Ecology https://orcid.org/0000-0001-7861-0958

Faith Jebiwot Kandie

Moi University

\section{Ulrike Fillinger}

ICIPE: International Centre for Insect Physiology and Ecology

\section{Francis McOdimba}

Egerton University - Njoro Campus: Egerton University

\section{Baldwyn Torto}

ICIPE: International Centre for Insect Physiology and Ecology

\section{Werner Brack}

Helmholtz-Zentrum für Umweltforschung UFZ: Helmholtz-Zentrum fur Umweltforschung UFZ

\section{Matthias Liess ( $\nabla$ matthias.liess@ufz.de)}

Helmholtz Centre for Environmental Research GmbH - UFZ. Department of System-Ecotoxicology, 04318 Leipzig, Germany https://orcid.org/0000-0002-3321-8909

\section{Henner Hollert}

Goethe University Frankfurt: Goethe-Universitat Frankfurt am Main

\section{Jeremias Becker}

Umweltbundesamt

\section{Research}

Keywords: Ecotoxicology, Bio-indicator, pesticide pollution

Posted Date: February 24th, 2021

DOI: https://doi.org/10.21203/rs.3.rs-252210/v1

License: (1) (1) This work is licensed under a Creative Commons Attribution 4.0 International License.

Read Full License 
1 Calibration of the SPEAR $\boldsymbol{R}_{\text {pesticides }}$ bioindicator for cost-effective pesticide 2 monitoring in East African streams

Akbar A. Ganatra ${ }^{1,2}$, Faith Jebiwot Kandie ${ }^{1,3,4,5}$, Ulrike Fillinger $^{1}$, Francis McOdimba ${ }^{1,2}$, Baldwyn Torto $^{1}$, Werner Brack ${ }^{3,5}$, Matthias Liess ${ }^{6,7}$, Henner Hollert ${ }^{7}$, Jeremias Becker ${ }^{6,7}$

${ }^{1}$ International Centre of Insect Physiology and Ecology (icipe), Human Health Theme, 00100

8 Nairobi, Kenya

9 2Egerton University, Biological Sciences, 20115 Egerton, Kenya

${ }^{3}$ Goethe University Frankfurt, Department Evolutionary Ecology and Environmental

Toxicology, Institute of Ecology, Evolution and Diversity, Faculty Biological Sciences, 60438 Frankfurt, Germany

${ }^{4}$ Department of Biological Sciences, Moi University, P.O. Box 3900-30100, Eldoret, Kenya.

${ }^{5}$ Department of Effect-Directed Analysis, Helmholtz Centre for Environmental Research

${ }^{6} \mathrm{Helmholtz}$ Centre for Environmental Research GmbH - UFZ. Department of SystemEcotoxicology, 04318 Leipzig, Germany

${ }^{7}$ RWTH Aachen University, Institute for Environmental Research (Biology V), 52074 Aachen,

Germany

corresponding author: Matthias Liess: matthias.liess@ufz.de

Key words

Ecotoxicology, Bio-indicator, pesticide pollution

\section{Abstract}

\section{Background}

Pesticides are washed from agricultural fields into adjacent streams where even short-term exposure causes long-term ecological damage. Detecting pesticide pollution in streams thus requires the expensive monitoring of peak concentrations during run-off events. Alternatively,

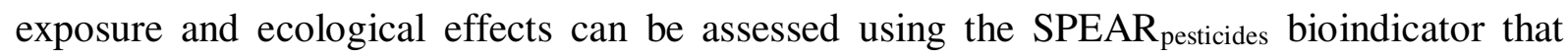
quantifies pesticide-related changes in the macroinvertebrate community composition.

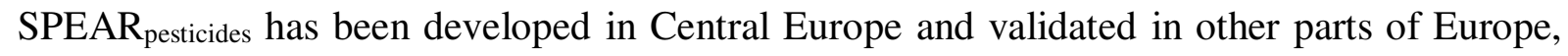
Australia and South America; here we investigated its performance in East African streams. 


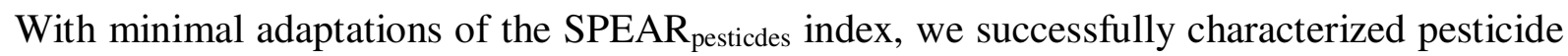
pollution in 13 streams located in Western Kenya. The East African SPEAR pesticides index correlated well with the overall toxicity of 30 pesticides (maximum toxic unit $=$ maximum environmental vs. median lethal concentration) measured in stream water $\left(R^{2}=0.53\right)$. Similarly,

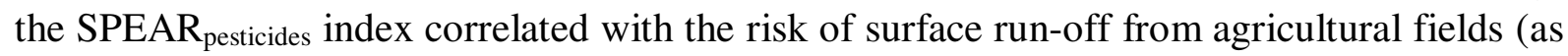
identified based on ground slope in the catchment area and the width of protective riparian strips, $\left.R^{2}=0.45\right)$. Unlike other bioindicators designed to indicate general water pollution,

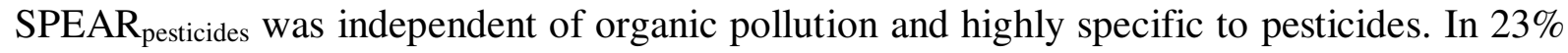
of the streams, pesticides exceeded concentrations considered environmentally safe based on European first tiered risk assessment.

\section{Conclusions}

Increasing contamination was associated with considerable changes in the macroinvertebrate community composition. We conclude that pesticides need to be better regulated also in

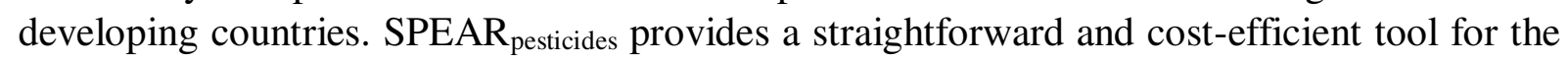
required monitoring of pesticide exposure in small to medium streams.

\section{Background}

In 2020, the worldwide application of agricultural pesticides is expected to increase from 2 million tonnes to 3.5 million tonnes annually (Sharma et al. 2019). Pesticide pollution is considered one of the main drivers for the global decline in the abundance and diversity of insects, plants and birds (Geiger et al. 2010, Beketov et al. 2013, Sánchez-Bayo and Wyckhuys 2019). There is increasing evidence that the pesticide-driven impairment of biocenoses also affects valuable ecosystem services ranging from pollination (Rundlöf et al. 2015) to leaf-litter degradation (Schaefer et al. 2011b) and to the biological control of agricultural pests (Talebi et al. 2008, Roubos et al. 2014) and of pathogens in freshwater (Becker et al. 2020a). For the United States and the European Union, where pesticides are used on a large scale, extensive literature on exposure and effects in the environment is available from academic research and from regulatory risk assessment (Sharma et al. 2019). In developing countries, regulation of plant protection products is often poor and information on pesticide pollution is scarce, though recent evidence suggests that pesticide usage has been increasing (Sharma et al. 2019). As agricultural producers grow more conscious about the use of synthetic pesticides and their toxic effects (Hernández et al., 2013), more effort in the assessment and mitigation of pesticide pollution is urgently needed.

Freshwater macroinvertebrates in small streams are at particular risk, since streams collect pesticide loads from agricultural fields in the catchment area (Münze et al. 2015). Moreover, many freshwater arthropods are highly sensitive to insecticides and fungicides (Von Der Ohe and Liess 2004, Van Dijk et al. 2013, Morrissey et al. 2015). However, the detection and quantification of pesticides in streams is challenging, as exposure occurs typically in short pulses due to spray drift and particularly due to surface run-off from agricultural fields following heavy rainfall (Liess et al. 1999). Such short-term exposure peaks (in the range of hours) drive long-term effects on the macroinvertebrate community for months (Liess and Schulz 1999, Cold and Forbes 2004, Beketov et al. 2008). Therefore, pesticide measurements 
from grab samples of stream water and sediment at random time points tend to considerably underestimate the magnitude of pesticide exposure. Realistic environmental monitoring in streams must capture the exposure peaks by run-off event-triggered sampling (Liess et al. 1999) or by continuous passive sampling over extended periods of time (Münze et al. 2015). However, such studies are labor-intensive and expensive (Vrana et al., 2005). In addition to the chemical analysis of samples for many compounds, samplers need to be installed, protected and regularly accessed in remote areas. These challenges limit the feasibility of monitoring pesticide pollution based on chemical analyses, particularly in developing countries.

As an alternative approach, pesticide exposure can be indirectly derived from its observed effects on the macroinvertebrate community composition. The SPEAR pesticides ("SPEcies At Risk") bioindicator has been developed to quantify decreases in the proportion of those taxa considered to be vulnerable to pesticides, as compared to reference conditions (Liess and von der Ohe 2005, Liess et al. 2008). For this task, stream macroinvertebrates have been classified as vulnerable or non-vulnerable taxa based on ecotoxicological traits (see methods). Because the SPEAR $\mathrm{R}_{\text {pesticides }}$ index describes the proportion of vulnerable taxa (weighted by individual number), it has no unit and does not facilitate the identification of individual toxic compounds in the environment. However, SPEAR pesticides values can be translated to an estimated toxic pressure for macroinvertebrates in the more informative form of toxic units (see methods).

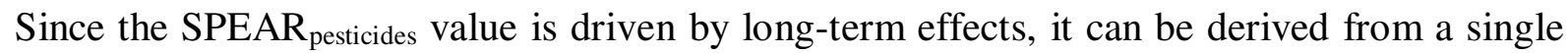

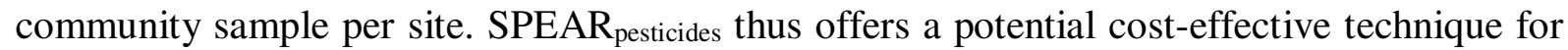
the monitoring of pesticide pollution in small to medium streams that may be specifically valuable in developing countries.

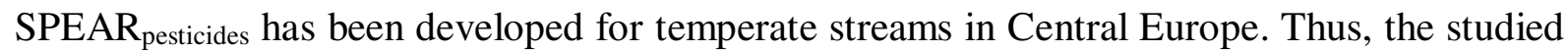
species composition, pesticide exposure patterns and ecological conditions may differ from those in other continents such as in sub-Saharan Africa. Malherbe et al. (2018) found only a

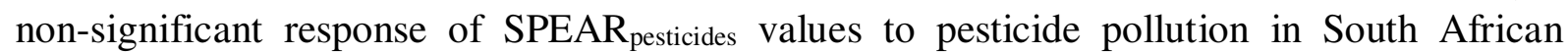
streams. In contrast, SPEAR $R_{\text {pesticides }}$ has been successfully applied and validated to assess pesticide pollution in various streams ranging from Southern to Northern Europe (Liess et al. 2008), and (after minor modification) in Australia (Schaefer et al. 2011a) and Argentina (Hunt

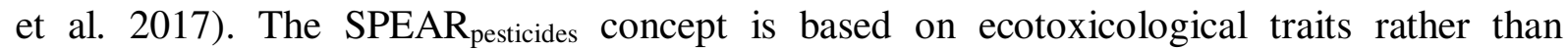
taxonomic relations and thus provides a mechanistic linkage of pesticide stress and the community response; in contrast to classical taxonomy-based bioindicators, trait-based approaches can overcome issues with natural taxonomic variability and may thus be applicable even across different climatic regions (Menezes et al. 2010). For freshwater macroinvertebrates in the Southern hemisphere, information on ecotoxicological traits is very scarce (Schaefer et al. 2011a, Malherbe et al. 2018). However, Wang et al. (2014) found that related saltwater invertebrates from temperate and tropical regions differ only slightly in their acute sensitivity

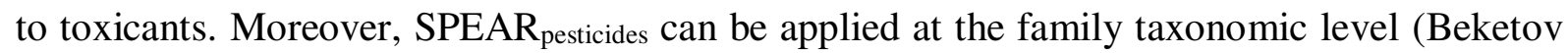
et al. 2009), and palearctic and afrotropical streams share most of their macroinvertebrate families (Ochieng et al. 2020). Assuming that families of freshwater macroinvertebrates from temperate and tropical streams may generally share their vulnerability to pesticides, SPEAR $_{\text {pesticides }}$ may be therefore used also in sub-Saharan Africa.

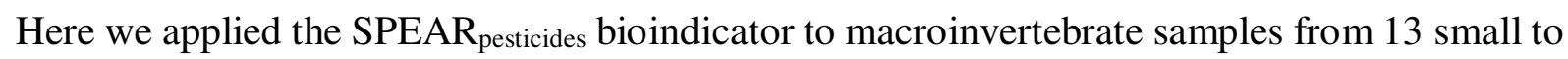

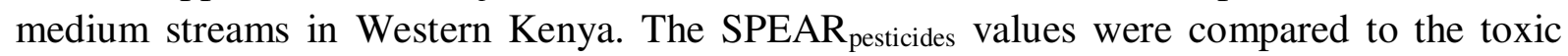
pressure of 30 pesticides in water samples concurrently collected during the rainy season

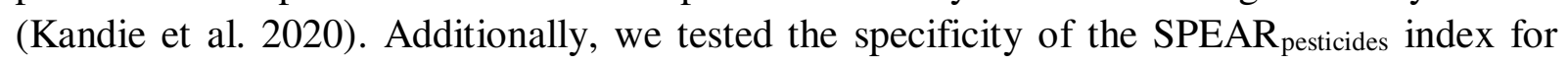


pesticide effects and compared its performance to alternative bioindicators for environmental stressors.

\section{Materials and methods}

\section{Study area}

128 The Lake Victoria South Basin in the western part of Kenya (Fig. 1) is characterized by a tropical climate with a major rainy season between March and June and a minor rainy season between October and December. The rainy seasons are separated by dry months, particularly in the lowlands close to the shore of Lake Victoria. The area is densely populated, but poorly developed in terms of infrastructure and sanitation. It is dominated by food production, mainly maize, for local markets with small scale fields that often range close to the unfortified banks of streams. However, large scale commercial farming also exists in the form of irrigated rice fields, sugarcane and particularly tea plantations (Wambugu and Muthamia 2009). During the rainy seasons, streams turn red from silt loads indicating heavy erosion and a high potential for surface run-off from agricultural fields.
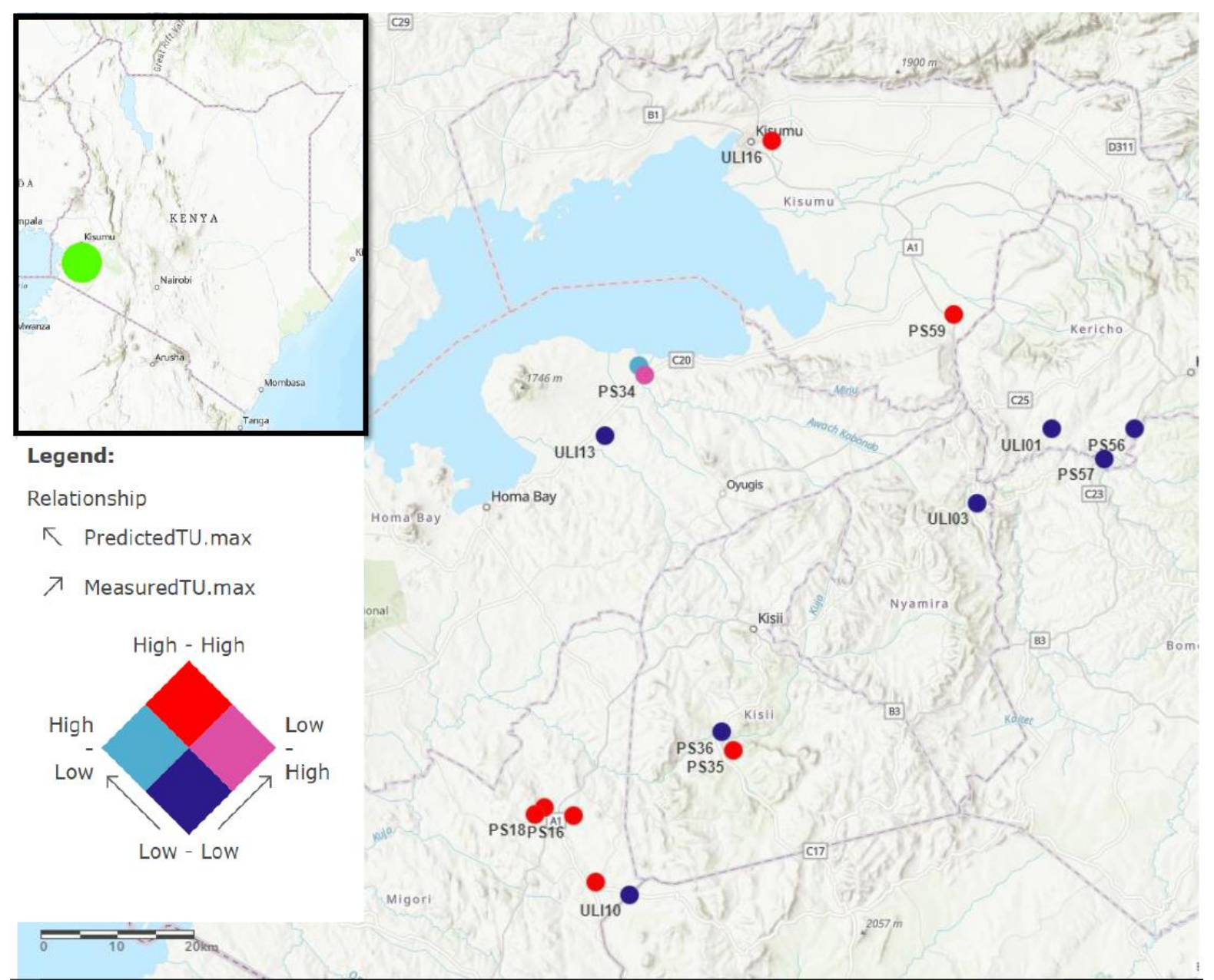

Figure 1: Location of the sampling sites in the study area of Western Kenya, East Africa. Site locations are displayed with the site code and colour-filled to annotate the relationship between predicted pesticide pollution ( $T U_{\max }$ ) using SPEAR pesticides and measured pollution in water samples using LC-HRMS in Kandie et al. (2020). Akbar Ganatra. "SPEAR pesticides study sites". "World Topographical map" \& 
145 The sampling and analysis of pesticide residues has been described in detail in Kandie et al. (2020). In brief, 48 sites covering small to large streams, oxbow lakes, irrigation channels, reservoirs and rice fields were sampled during the rainy season in September - October 2017. A single $500 \mathrm{~mL}$ water sample per site was collected in a pre-cleaned glass. Solids were allowed to settle for $1 \mathrm{~min}$, before aliquots of $1 \mathrm{~mL}$ were transported to the laboratory in amber glass vials at $-4^{\circ} \mathrm{C}$. Chemical analysis was performed by directly injecting $100 \mu \mathrm{L}$ of the water sample into a high performance liquid chromatography system (Thermo Ultimate $3000 \mathrm{LC}$ ) coupled to a high resolution mass spectrometer (QExactive Plus, Thermo). The water samples were subjected to target screening for 428 chemicals and to suspect screening for 233 additional substances. This analysis included 162 hydrophilic pesticides (active substances and metabolites), but no highly hydrophobic compounds such as pyrethroid insecticides for which different sampling techniques are required. Raw data was processed using MZmine (Version 2.38, Pluskal et al., 2010) and further confirmation and quantification done using TraceFinder 4.1 (Thermo) as detailed in Kandie et al. 2020. Physicochemical water parameters were measured in situ (flow velocity, temperature, dissolved oxygen, phosphates, $\mathrm{pH}$, turbidity) and from additional water samples in the laboratory (nitrate, nitrite, ammonium, carbonate hardness).

162 In the present study, we only considered pesticides and converted the observed concentrations in the water samples to toxic units in order to quantify the toxic pressure for freshwater macroinvertebrates. The toxic unit (TU; Sprague 1970) describes the environmental concentration conc of a pesticide $i$ in relation to its median effective or lethal concentration ( $E C_{50}$ or $L C_{50}$, concentration that affects or kills $50 \%$ of individuals in an acute toxicity test)

Eq 1:

$$
T U_{i}=\frac{\operatorname{Conc}_{i}}{\operatorname{LC50}_{i}}
$$

For the TU calculation we generally referred to the $\mathrm{LC}_{50}$ for the water flea Daphnia magna after constant exposure for $48 \mathrm{~h}$ as reported in the Pesticides Properties Data Base (PPDB, 2019). D. magna was selected as a reference because it belongs to the more sensitive freshwater macroinvertebrates and because most toxicological data are available for this species due to its use in regulatory risk assessment (Brock and Van Wijngaarden 2012). However, for some pesticides (particularly neonicotinoid insecticides), D. magna turned out to be considerably more tolerant than other macroinvertebrates (Brock and Van Wijngaarden 2012). Therefore, we additionally extracted the $\mathrm{LC}_{50}$ for the saltwater shrimp Americamysis bahia after $96 \mathrm{~h}$ exposure from the PPDB data base in case it was available. In cases where D. magna was highly insensitive $\left(\mathrm{LC}_{50}>10 \mathrm{mg} / \mathrm{L}\right.$ ), we additionally took data from the ECOTOX data base (ECOTOX 2019) for the standard test species Chironomus riparius and Hyalella azteca. If the $\mathrm{LC}_{50}$ of $D$. magna was $>10$ times higher than that of an additional species observed after $48 \mathrm{~h}$ or $>100$ times higher after $96 \mathrm{~h}$, we used the most sensitive additional species as reference (mean $\mathrm{LC}_{50}$ from different studies in ECOTOX, if available). For metabolites we used the $\mathrm{LC}_{50}$ of the parental compound if no toxicity data was available or if the metabolite was less toxic

185 The overall toxic pressure from pesticide mixtures in the water samples was summarized as the 
toxic unit. $\mathrm{TU}_{\max }$ and $\mathrm{TU}_{\text {sum }}$ were set to a minimum threshold of $10^{-4}$ for sites at which no potentially relevant concentrations were detected; this threshold is in the range of the limit of quantification for the most toxic pesticides in the chemical analysis (see supplementary material). Additionally, no effects of pesticides on freshwater macroinvertebrate communities have been generally observed in the field below a threshold range of $\mathrm{TU}_{\max }$ between $10^{-3}$ and

$19210^{-4}$ (Schaefer et al. 2012).

\section{The SPEAR pesticides $_{\text {concept }}$}

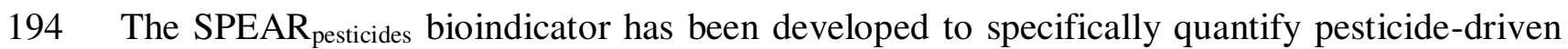
deviations in the community structure from those observed under non-polluted reference conditions. Since its first publication in Liess and von der Ohe (2005), SPEAR pesticides $_{\text {has }}$ been constantly refined (Liess et al. 2008, Beketov et al. 2009). Here we refer to the latest version 2019.11 that includes some major improvements described in Knillmann et al. (2018).

SPEAR $_{\text {pesticides }}$ is based on a classification of freshwater macroinvertebrates in" SPEcies At Risk" and in taxa being not at risk based on four traits that describe their vulnerability to pesticides: 1.) the average physiological sensitivity to various pesticides ( $s$-value, mean of $\log _{10}\left(\mathrm{LC}_{50}\right.$ relative to the $\mathrm{LC}_{50}$ of the reference species D. magna or Chironomus sp. $)$ ); 2.) the ability of autochthonous population recovery from reproduction (generation time); 3.) the ability of allochthonous recovery from recolonization (dispersal from non-polluted refuge areas); and 4.) the probability of being actually exposed (e. g. aquatic life stages during the main insecticide application season). Taxa with high sensitivity, low ability of autochthonous and allochthonous recovery and high probability of being exposed have been classified as being at risk, others as not at risk. A trait data base for Central European taxa, linked to a program for the calculation of SPEAR pesticides values is available with the software INDICATE (htpp://www.systemecology.eu/indicate). The data base comprises entries for individual species, but also for higher taxa where available data on lower taxonomic levels have been averaged.

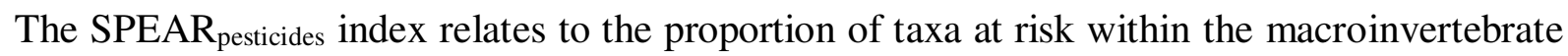
community and decreases with increasing toxic pressure (Knillmann et al. 2018):

Eq 2:

$$
S P E A R_{\text {pesticides }}=\frac{\sum_{i=1}^{n} \log _{10}\left(4 x_{i}+1\right) \cdot y}{\sum_{i=1}^{n} \log _{10}\left(4 x_{i}+1\right)}
$$

with $x_{i}$ being the observed number of individuals of taxon $i$, and $y$ being 1 for those taxa

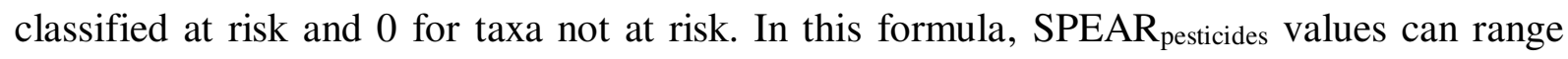
between 0 (no species at risk, indicating high pesticide effects) and 1 (only species at risk). Abundant taxa are down weighted to limit the influence of populations with mass development

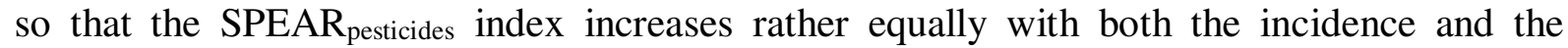
population density of vulnerable taxa. In order to facilitate interpretation, since version 2019.11,

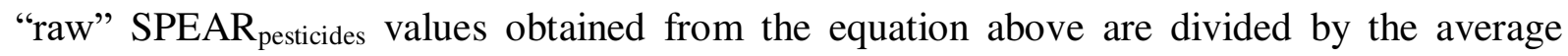
SPEAR $R_{\text {pesticides }}$ value observed in non-polluted reference sites (at measured $\mathrm{TU}_{\max }<10^{-4}$ ) from Germany (Knillmann et al. 2018):

Eq 3: 


$$
\text { scaled } S P E A R_{\text {pesticides }}=\frac{\text { raw } S P E A R_{\text {pesticides }}}{\text { reference } S P E A R_{\text {pesticides }}}
$$

With reference $S P E A R_{\text {pesticides }}=0.27$. This scaled $S P E A R_{\text {pesticides }}$ index ranges from 0 (no species at risk) to 3.7 (only species at risk) and indicates no toxic pressure at values $>1$. For European streams, an empirical relationship between SPEAR pesticides and the measured $\log _{10-}$ transformed $\mathrm{TU}_{\max }$ during run-off events has been established to convert SPEAR pesticides values to the estimated toxic pressure (Liess et al. 2008, Knillmann et al. 2018). Because the community composition of Kenyan freshwater macroinvertebrates may differ from those in Germany, both the classification of individual taxa and the conversion to $\mathrm{TU}_{\max }$ were subjected to revision in the present study (see results).

\section{Application of SPEAR $R_{\text {pesticides }}$ in the study area}

We applied SPEAR pesticides to macroinvertebrate samples collected together with the water samples from Kandie et al. (2020, see above). The macroinvertebrate sampling has been described in detail in Becker et al. (2020a). In brief, macroinvertebrates were collected at the same site and day as the water samples, following a standardised approach adapted from the South African Scoring System 5 (SASS5, Dickens and Graham 2002). At each stream site, a $50 \mathrm{~m}$ stretch was sampled in four quadrants by two persons in parallel. Each quadrant was sampled for 7 minutes using sweep nets for the water surface and littoral habitats, and kick sampling for the benthic macroinvertebrates. Additionally, gravel, soil and mud (GSM) habitats were sampled for 1 minute per quadrant. Organisms were preserved in $70 \%$ ethanol and identified to the family level under a dissecting microscope in the laboratory. SPEAR pesticides $\mathrm{V}$. 2019.11 and the associated estimated $\mathrm{TU}_{\max }$ were calculated using the software INDICATE $\mathrm{v}$. 1.2.0 (htpp://www.systemecology.eu/indicate).

\section{Application of other indicators of freshwater pollution}

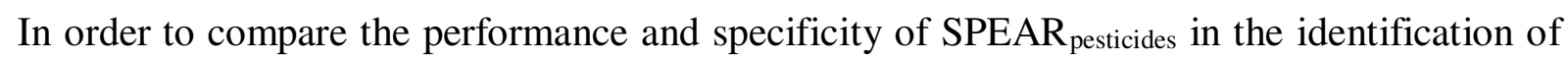
pesticide pollution, we additionally applied the Biological Monitoring Working Party (BMWP) and the South African Scoring System (SASS5) bioindicators for freshwater quality. In contrast

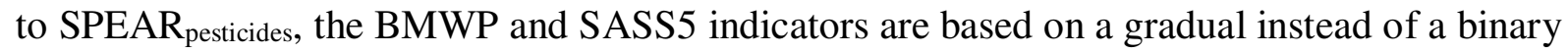
classification system for the sensitivity of freshwater macroinvertebrates (mainly to low oxygen levels) ranging from 1 to 10 . Like SPEAR pesticides, the indicators have been established for freshwater families from a different region, but have been also applied in sub-Saharan Africa beyond their countries of origin (Bere and Nyamupingidza 2014, Ochieng et al. 2020)

The BMWP score system was developed in the 1980s and refined later to assess organic pollution in British streams (Paisley et al. 2014). For a refined assessment according to the European Water Frame Work Directive, ecological quality indices are derived from the BMWP score by comparing observed vs. expected values based on an elaborate stream classification system. Such a classification system is not available for Kenyan streams; therefore, we simply calculated the average score per taxon (ASPT) using the software ASTERICS AQUEM/STAR Ecological River Classification System v. 4.0.4, (https://www.gewaesserbewertung.de/index.php?article_id=419\&clang=0). SASS5 was originally developed in 1994 and refined in 2002 to determine the condition or 'health' of rivers in South Africa (Dickens and Graham 2002). As recommended, we calculated the Average Score Per Taxa (ASPT) using the score tables available in Dickens and Graham (2002). 
Finally, we calculated the proportion of ephemeropteran, plecopteran and trichopteran insects on the overall individual number (EPT) and the species diversity (Shannon index) as more general descriptors of the freshwater macroinvertebrate community. Both descriptors are considered to decrease with increasing levels of water pollution (Knillmann et al. 2018).

Additionally we estimated the run-off potential of a site, i. e. a predictor for the risk of pesticide exposure from surface run-off (Schriever et al. 2007). We used a highly simplified approach by classifying sites on an ordinal scale based on the average local ground slope and the average width of riparian strips up to $2 \mathrm{~km}$ upstream as visible from online satellite imagery. Slope was classified as flat, low, medium and high. The run-off potential was then classified as follows: 1 (none): $\geq 30 \mathrm{~m}$ buffer strip, or $\geq 20 \mathrm{~m}$ buffer strip and flat or low slope; 2 (low): $21-30 \mathrm{~m}$ buffer strip, or $11-20 \mathrm{~m}$ buffer strip and flat or low slope; 3 (moderate): $11-20 \mathrm{~m}$ buffer strip, or $6-10 \mathrm{~m}$ buffer strip and flat or low slope; 4 (high): $\leq 10 \mathrm{~m}$ buffer strip, or $\leq 5 \mathrm{~m}$ buffer strip and flat or low slope.

283

284

285

286

287

288

289

\section{Data analysis}

Data analysis was performed using $\mathrm{R}$ version 3.6.2. Because $\mathrm{SPEAR}_{\text {pesticides }}$ has been developed for small and medium streams with flowing water, we limited our analysis to samples from natural streams (no artificial channels) with an average width of $<20 \mathrm{~m}$ and an estimated average flow velocity $>1 \mathrm{~cm} / \mathrm{s}$ (based on the drift-body method). Two sites from a small river close to Kisii (PS42 and PS43, see supplementary information) were excluded because biological sampling took part during high water. These samples were characterized by low numbers of taxa and individuals, as well as unusually high pesticide concentrations as compared

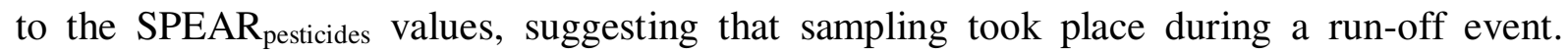

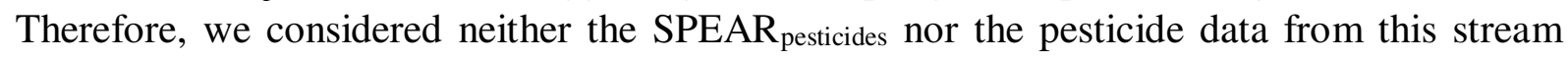
comparable to the other sites. Altogether, our analysis included 16 sites from 13 different streams. Three of the streams were sampled twice, with an average distance of ca. $2 \mathrm{~km}$ between both sites. Macroinvertebrate samples and toxic units from sites of the same stream were considerably more similar than those from different streams; to avoid pseudo-replication we therefore aggregated data from different sites of the same stream using the mean values.

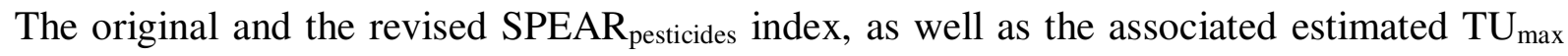
were compared to the $\mathrm{TU}_{\max }$ from pesticide measurements using one-way linear regression; $\mathrm{TU}_{\max }$ was $\log _{10}$-transformed prior to the analyses. To assess the potential disturbance of the sampling sites by additional stressors other than pesticides, we investigated the distribution of the measured $\mathrm{TU}_{\max }$ and physicochemical water parameter values using violin plots; the data were compared to thresholds for a good ecological status from the literature. To assess the

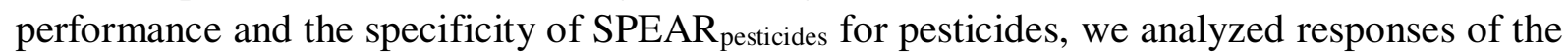
SPEAR $_{\text {pesticides }}$ index and of the additional bioindicators and descriptors to the physicochemical

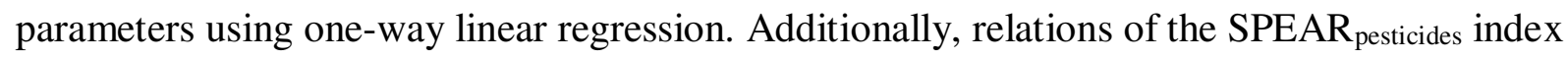
and those physicochemical parameters that had a (marginally) significant effect on the SPEAR $_{\text {pesticides, }}$ BMWP or SASS5 bioindicator were summarized using a principal component analysis (PCA). Finally, we performed pairwise correlations among the bioindicators and among those environmental variables that significantly affected these bioindicators in order to identify confounding factors. 


\section{Results}

\section{Pesticide pollution and effects on the macroinvertebrate community}

313 We observed considerable pesticide toxicity to freshwater macroinvertebrates in our 16 study 314 sites from 13 streams, quantified as the maximum toxic unit derived from chemical water analyses ( $\mathrm{TU}_{\max }$, see methods). $\mathrm{TU}_{\max }$ exceeded the threshold range for environmental effects of $10^{-4}$ to $10^{-3}$ (Schaefer et al. 2012) in nine and eight streams, respectively. The results indicate that pesticide pollution was a relevant environmental stressor in the study area. Pesticide toxicity was driven by the insecticides diazinon ( 7 sites, $\left.\mathrm{TU}=10^{-2.36}-10^{-1.81}\right)$, pirimiphosmethyl ( 3 sites, TU $\left.=10^{-1.86}-10^{-1.21}\right)$, bendiocarb $\left(1\right.$ site, $\left.\mathrm{TU}=10^{-2.54}\right)$ and imidacloprid $(1$ site, $\left.\mathrm{TU}=10^{-3.47}\right)$.

321 Overall, we identified 35 macroinvertebrate families in the streams. The proportion of taxonomic groups changed markedly with increasing pesticide toxicity (Fig. 2). Non- or marginally polluted sites with $\mathrm{TU}_{\max }<10^{-3}$ were dominated by the ephemeropteran families Baetidae and Heptageniidae, the zygopteran family Coenagrionidae, the heteropteran families Gerridae and Veliidae, and by the coleopteran family Gyrinidae. These families occurred in at least half of the low-polluted streams and also showed the highest proportions on the mean number of individuals collected in a low-polluted stream (relative abundances). The same families occurred also in at least half of the highly polluted streams with $\mathrm{TU}_{\max } \geq 10^{-3}$, but additionally the ephemeropteran family Caenidae, the anisopteran family Libellulidae, the heteropteran families Naucoridae and Nepidae, and snails of the family Planorbidae were observed in the majority of these streams. As the most prominent changes in the community composition, the mean relative abundance of Baetidae decreased from $56 \%$ (range: 7 - $94 \%$ ) in lowly polluted streams to $10 \%$ (range: $0.2-38 \%$ ) in highly polluted streams $(n=5$ lowly and 8 highly polluted sites, $\chi^{2}=8.29, p=0.004$ using a binomial generalized linear model). At the same time, Planorbidae increased from $0 \%$ to $9 \%$ (range: $0-36 \%, \chi^{2}=7.95, p=0.005$ ) in highly polluted streams. Therefore, changes in the community composition with pesticide pollution were driven by the response of frequently occurring taxa, suggesting that $\mathrm{SPEAR}_{\text {pesticides }}$ may perform consistently across random samples from different streams. The results are consistent with Reiber et al. (2020) who identified mayflies and snails among those macroinvertebrate taxa that most strongly decrease or increase with pesticide pollution in European streams, respectively. 


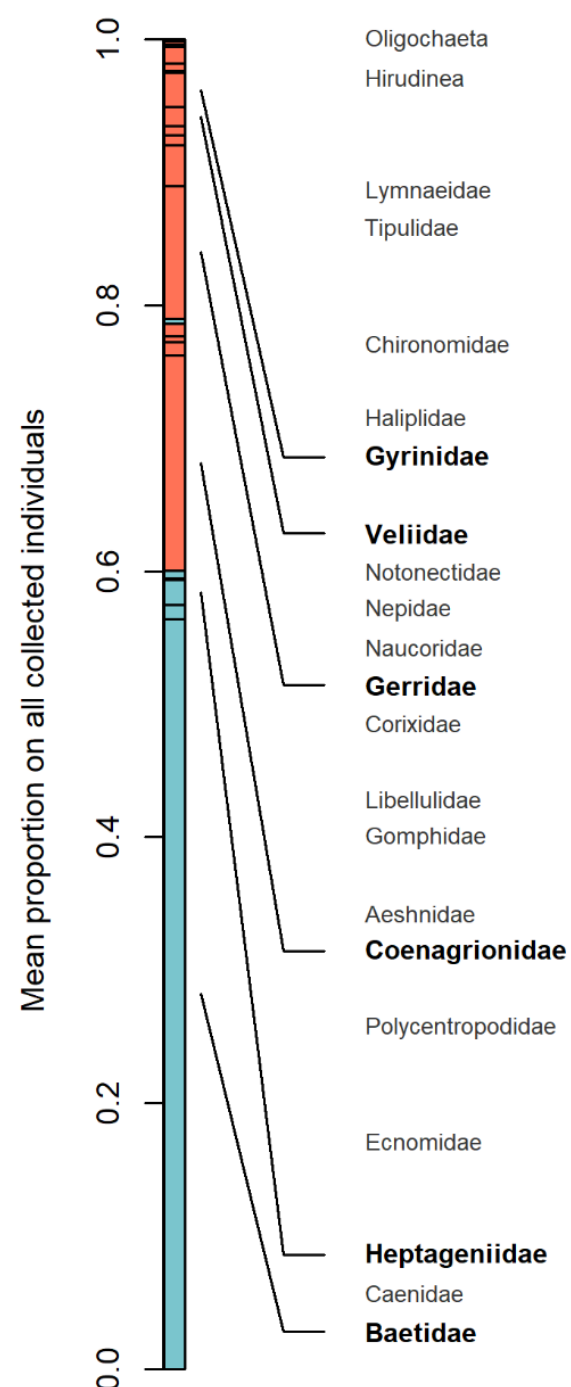

Lowly polluted streams
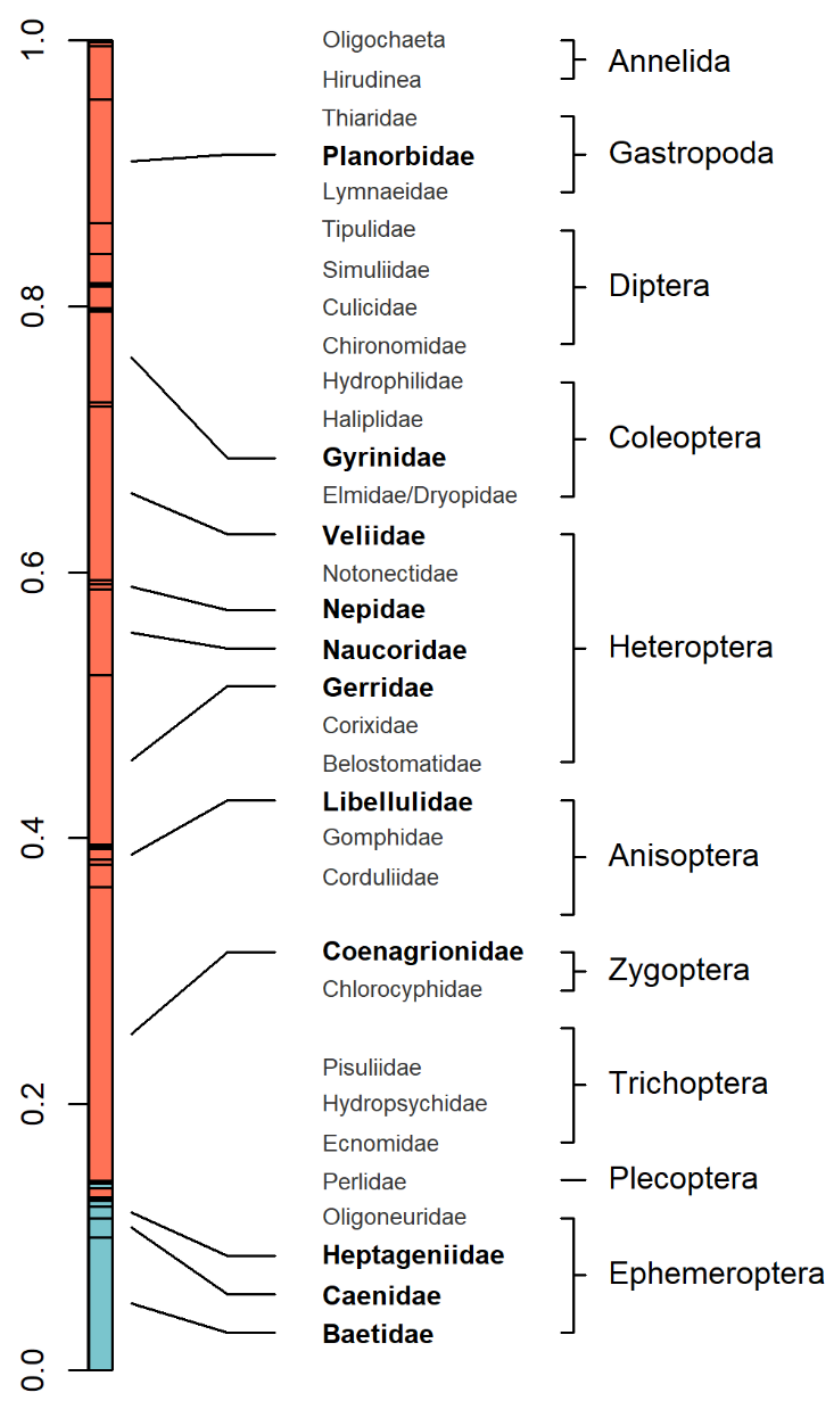

Highly polluted streams

Figure 2: The freshwater macroinvertebrate community composition changes in streams with high pesticide pollution. The stacked bars show the mean proportions of macroinvertebrate families on the overall number of individuals observed in lowly-polluted (maximum toxic unit $\mathrm{TU}_{\max }<10^{-3}$ ) and in highly polluted streams $\left(\mathrm{TU}_{\max } \geq 10^{-3}\right.$ ). The number of individuals ranged from 32 to 154 (mean: 94) in the 5 lowly polluted streams and from 37 to 462 (mean: 152 ) in the 8 highly polluted streams. Families that were recorded in at least $50 \%$ of the streams are shown in in bold. Taxa shown in blue have been classified as being at risk in the adapted SPEAR pesticides indicator for East African streams, taxa shown in red have been classified not at risk.

\section{Adaptation of SPEAR pesticides to East African streams}

Most of the 35 macroinvertebrate families sampled were automatically linked to existing taxa in the trait database provided in the software INDICATE (see Tab. S2 in the supplementary material). Only three families were not existing in the database because they do not occur in Central European streams; these families were manually linked to higher taxa available in the database: Pisuliidae was linked to Trichoptera Gen. sp., Oligoneuridae was linked to 
Ephemeroptera Gen. sp., and Chlorocyphidae was linked to Zygoptera Gen. sp. Culicidae was automatically linked to Diptera Gen. sp., but traits are missing for this taxon (due to a lack of data because dipteran species are too heterogeneous to be aggregated), and they were therefore automatically excluded from the calculation of SPEAR pesticides.

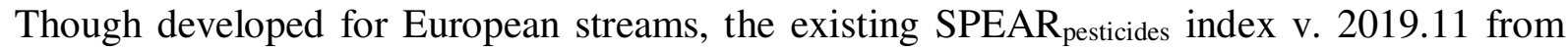
Knillmann et al. (2018) a showed reasonable correlation with the measured pesticide toxicity $\left(\mathrm{TU}_{\max }\right)$ from chemical water analysis when applied to the Kenyan macroinvertebrate communities $\left(R^{2}=0.43\right.$, Fig. 3a). The correlation of the SPEAR pesticides index with toxic pressure increased when we re-classified two taxa based on additional information for Kenyan taxa. First, the damselfly family of Coenagrionidae has been classified at risk in the European SPEAR pesticides index v. 2019-11, based on a relatively high physiological insecticide sensitivity $(s$-value $=-0.24)$. This value is only slightly above the threshold for sensitive taxa $(s \geq-0.36)$. The classification was based on toxicity data for the European species Eschnura elegans. However, acute toxicity tests with the insecticides diazinon and imidacloprid on freshwater macroinvertebrates collected in the study region of Western Kenya revealed that the tolerance of local coenagrionid species is comparable to those of other taxa such as Notonectidae, Chironomidae and Dytiscidae that have been classified as insensitive (Becker et al. 2020a). Accordingly, we re-classified Coenagrionidae as being insensitive ( $s$-value $=-0.4)$; consequently, the taxon moved from the category "at risk" to "not at risk".

Second, in SPEAR pesticides v. 2019.11, the heteropteran family Corixidae was considered as nonexposed due to a surrounding layer of air (physical lung) that potentially protect individuals from pesticide exposure in the water. However, in acute toxicity tests we observed high insecticide sensitivity of Corixidae from the study region (Becker et al. 2020a). Thus, we reclassified Corixidae as being exposed, so that the taxon moved from the category "not at risk" to "at risk". Results of toxicity tests with additional 13 taxa collected in the study region from Becker et al. (2020a) were in accordance with the existing classification in the SPEAR pesticides trait data base.

With these changes, we were able to adapt the SPEAR pesticides index to East African streams so that it explained the observed $\mathrm{TU}_{\max }$ considerably better than the European SPEAR pesticides index

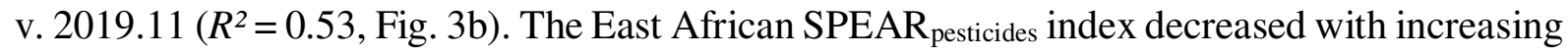
measured pesticide toxicity as follows:

390 Eq. 4:

$$
\text { SPEAR } \text { pesticides }=-0.43 * \log _{10}\left(\text { background } T U_{\max }\right)-0.02
$$

392 After solving equation 4 for $\mathrm{TU}_{\max }$, the East African $\mathrm{SPEAR}_{\text {pesticides }}$ index may be used to predict 393 background toxicity in streams from the observed macroinvertebrate community composition:

394 Eq. 5: 
(a)

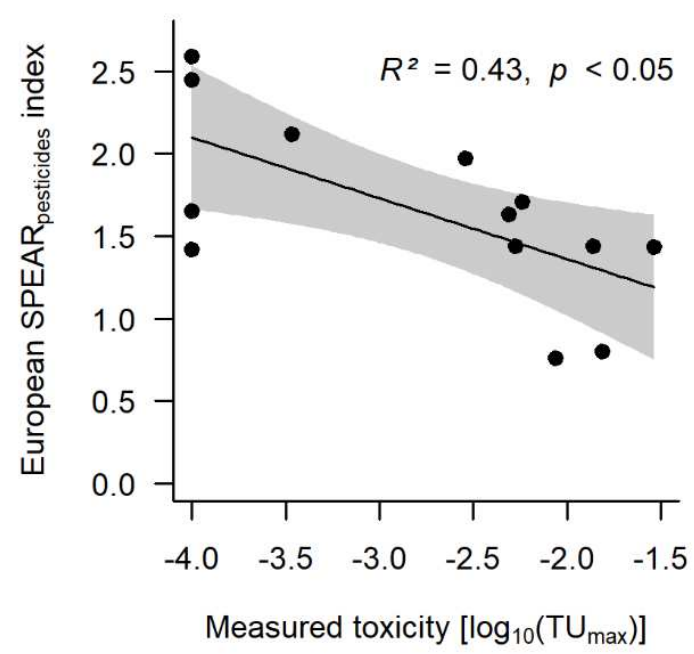

(b)

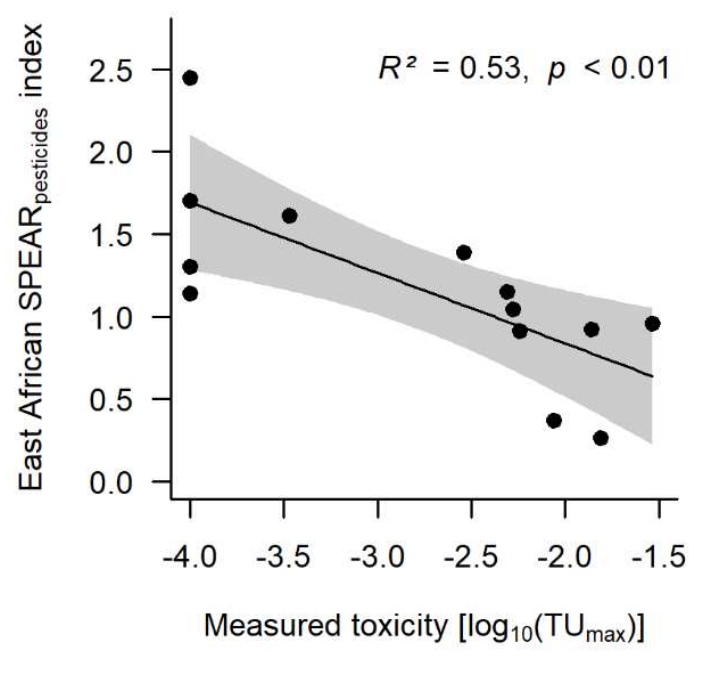

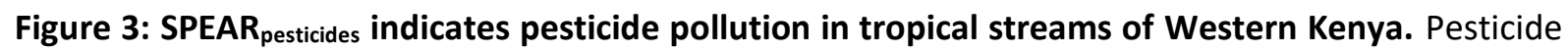
pollution was quantified as the maximum toxic unit $\left(T U_{\max }\right.$, restricted to $\left.\geq 10^{-4}\right)$ out of 30 pesticides measured in water samples collected during the rainy season but not during peak exposure. Freshwater macroinvertebrates were identified to the family level. (a) Application of the European SPEAR pesticides index v. 2019.11 from Knillmann et al. (2018) to the Kenyan samples; $R^{2}=0.43, F=8.15$, $\mathrm{df}=1$, res. $\mathrm{df}=11, p=0.016$, intercept $=0.62$, slope $=-0.37$. (b) Application of the SPEAR pesticides index after adaption to East African streams. $R^{2}=0.53, F=12.35, \mathrm{df}=1$, res. $\mathrm{df}=11, p=0.005$, intercept $=$ 0.02 , slope $=-0.43$.

The mean $\mathrm{TU}_{\max }$ predicted from equation 5 and the mean observed background $\mathrm{TU}_{\max }$ coincided well (difference by a factor of $<2.5$ or of $\leq 0.4$ orders of magnitude $\left(=\log _{10}\right.$-transformed $\mathrm{TU}_{\max }$ ) across the whole range of observed toxicity, Fig. 4a). Across all data points, the ratio of estimated vs. measured $\mathrm{TU}_{\max }$ ranged from 0.2 to 19.6 , i. e. the predicted toxicity deviated from the measured toxicity by $<1.3$ orders of magnitude in all investigated streams.

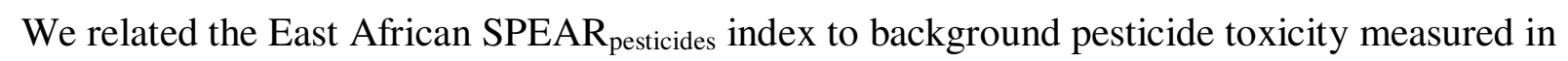
water from grab samples collected during the rainy season, but outside run-off events. In

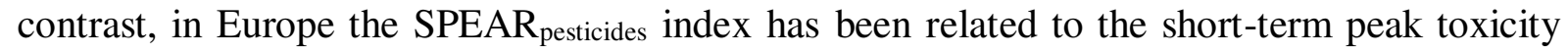
measured during run-off events following heavy rainfall (Liess and von der Ohe 2005, Liess et al. 2008, Knillmann et al. 2018). In temperate streams of Europe and North America, peak pesticide toxicity is approximately four times as high as the background toxicity during the season of main pesticide exposure in early summer (Williams et al. 1995, Kreuger 1998, Liess et al. 1999, Schäfer et al. 2008, Münze et al. 2017). Assuming that the same ratio of peak vs. background toxicity may hold also in tropical streams, we applied a correction factor of 4 to relate the East African SPEAR pesticides index to an estimated peak exposure during run-off:

Eq. 6:

$$
\text { estimated peak } T U_{\max }=4 * 10^{\frac{S P E A R_{\text {pesticides }}+0.02}{-0.43}}
$$

The response of the East African SPEAR could then be compared to the response of the latest European SPEAR pesticides index v. 2019.11 
to peak exposure in Germany (Knillmann et al. 2018). The East African SPEAR pesticides index produced considerably higher numbers as compared to the European index, particularly when pesticide toxicity was low (Fig. 4b). The more pronounced increase in the East African SPEAR $R_{\text {pesticides }}$ index with decreasing pesticide exposure indicates differences in the composition of European and East African macroinvertebrate communities and in their response to pesticides. Therefore, the use of a separate conversion scheme from SPEAR pesticides to $\mathrm{TU}_{\max }$ in afrotropical streams, as established with equation 5 and 6 , is justified.

To assess the reproducibility and robustness of the East African SPEAR pesticides index, we extended our data set to all sites sampled in the study area of Western Kenya (see Becker et al. 2020a). The 48 sites from 40 water bodies included habitats for which SPEAR pesticides was not designed such as artificial irrigation channels, rice fields, reservoirs, oxbow lakes and large rivers. We still observed a relation of the East African $S_{P E A R}$ pesticides index with $\mathrm{TU}_{\max }$ that was very similar to those in Fig. $3 \mathrm{~b}$, but the non-explained variation increased considerably $\left(R^{2}=\right.$ $0.13, F=5.55$, df $=1$, res. $\mathrm{df}=38, p=0.024$, intercept $=0.13$, slope $=-0.31$ ).

(a)

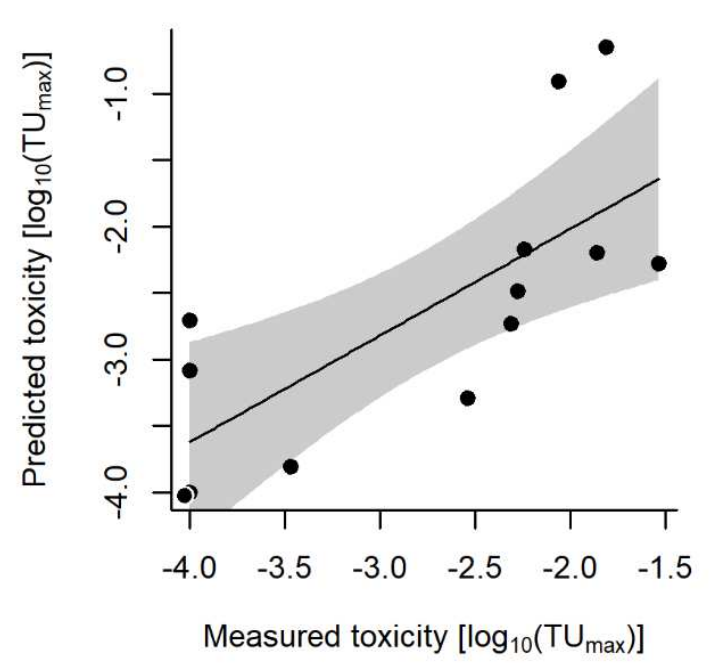

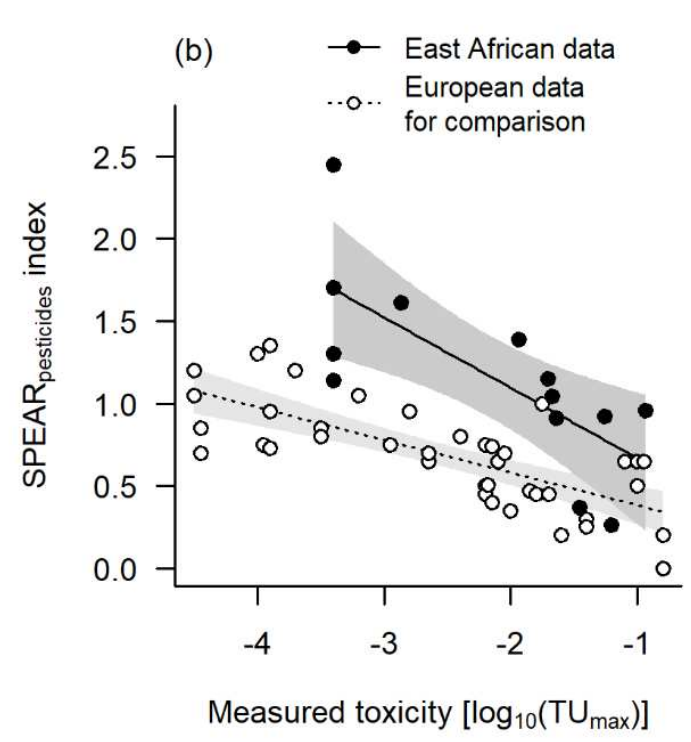

442

443

444

445

446

447

448

449

450

451

452

453

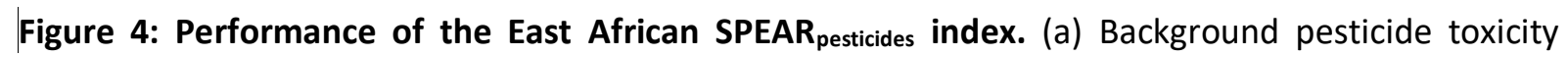
(maximum toxic unit, $\mathrm{TU}_{\max }$ ) predicted with the East African SPEAR $\mathrm{R}_{\text {pesticides }}$ index correlates with the measured background toxicity in Kenyan water samples. $R^{2}=0.54, F=12.97$, df $=1$, res. $\mathrm{df}=11, p=$ 0.004 , intercept $=-0.41$, slope $=0.80$. $\mathrm{TU}_{\max }$ was restricted to $\geq 10^{-4}$, because lower toxicity could not be measured due to detection limits for pesticides. TU $\max$ has been $\log _{10}$-transformed, so that differences are presented in orders of magnitude. (b) Relation of the East African SPEAR pesticides index with the estimated peak pesticide toxicity during run-off in Kenyan streams, as compared to the

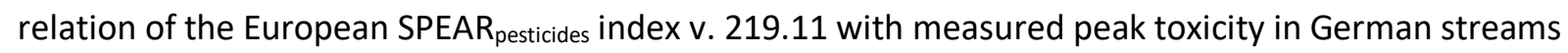
(data from Knillmann et al. 2018). Peak exposure in Kenyan streams was estimated by multiplying the measured background toxicity with a correction factor of 4 (see main text for justification). 


\section{Specificity of the East African SPEAR $\mathbf{R}_{\text {pesticides }}$ index to pesticides}

455 To assess the potential impact of confounding factors and the specificity in the response of the

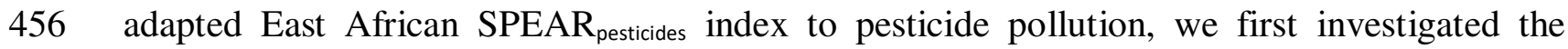
457 potential influence of additional physicochemical parameters on the macroinvertebrate 458 community. A comparison of the observed physicochemical water parameters with values 459 recommended for good water quality from the literature revealed that pesticide pollution was 460 indeed one of the dominant stressors at the sampling sites (Fig. 5). Additionally, in many 461 streams we observed very high levels of phosphate and turbidity, as well as low levels of 462 carbonate hardness and dissolved oxygen, which may have contributed in shaping the 463 macroinvertebrate community.

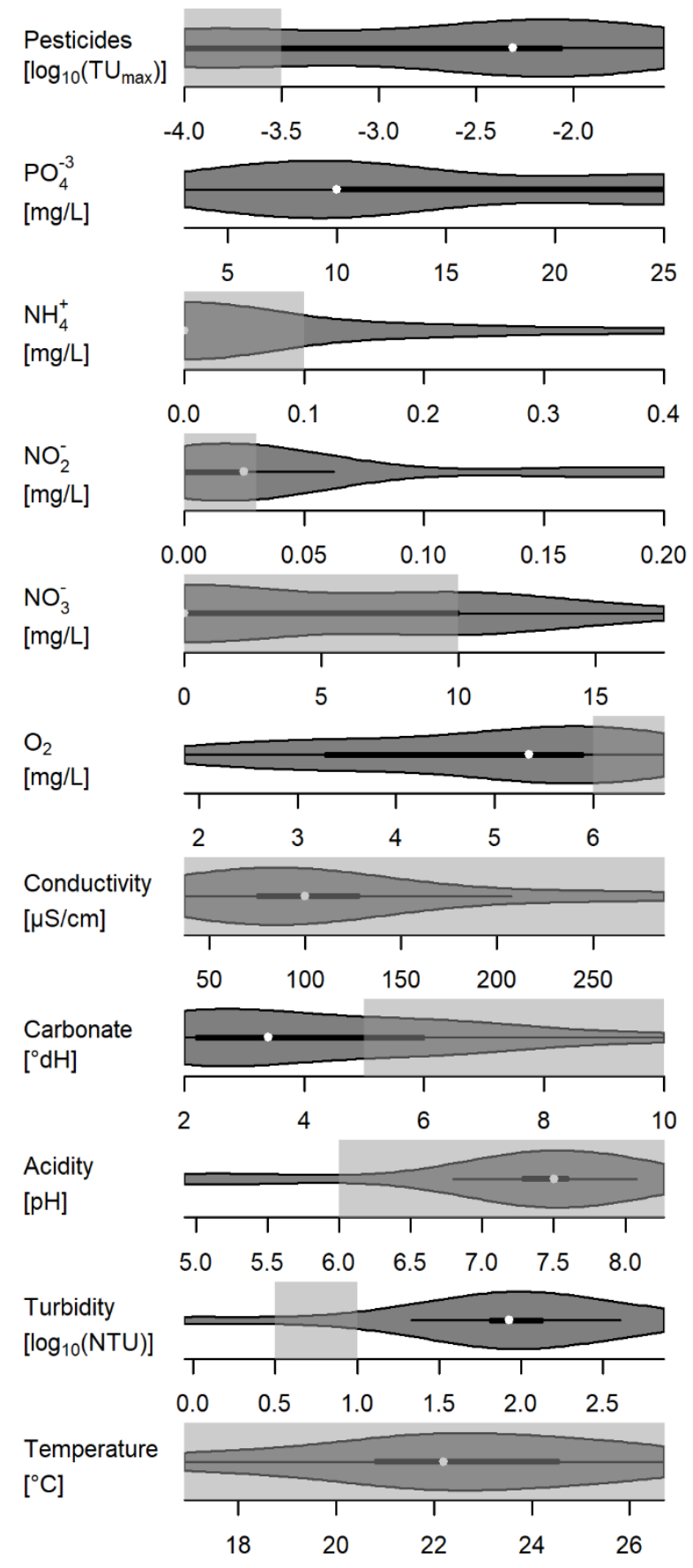


Figure 5: Distribution of physicochemical parameter values at the study sites. The violin plot shows the kernel probability density of the data points across the parameter values. White points indicate the median, black boxes the interquartile range, and black lines $1.5 \mathrm{x}$ the interquartile range. Lightgrey boxes indicate the range of values considered typical or recommend for streams with good water quality.

Next, we assessed the sensitivity of the adapted SPEAR pesticidess index for East Africa to such

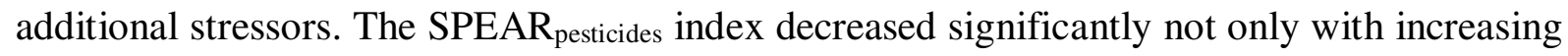
pesticide toxicity (measured $\mathrm{TU}_{\max }$ and $\mathrm{TU}_{\text {sum }}$ ) and run-off potential, but also with carbonate hardness, conductivity and turbidity (Tab. S1 in the supplementary material). However, pesticide toxicity was significantly correlated with each of these confounding factors (Tab. S2 in the supplementary material). All these factors were associated with a dominant environmental gradient identified by the first principal component in a principal component analysis (PCA). This gradient explained $61 \%$ of the total variation and likely reflects a range of different stream types (Fig. 6). On one end, lowly polluted, fast-flowing mountain streams showing high SPEAR pesticides values (streams nr. 27, 28, 31 and 32) were running in comparably steep valleys through intensely cultivated tea plantations but were protected from run-off by wide buffer strips so that run-off potential and pesticide toxicity was low. On the other end, lowland streams were slowly flowing and showed higher run-off potential due to surrounding agriculture with only small buffer strips. These streams showed high pesticide toxicity, as well as sediment (turbidity) and phosphate pollution that were associated with low SPEAR pesticides values and high conductivity, respectively.

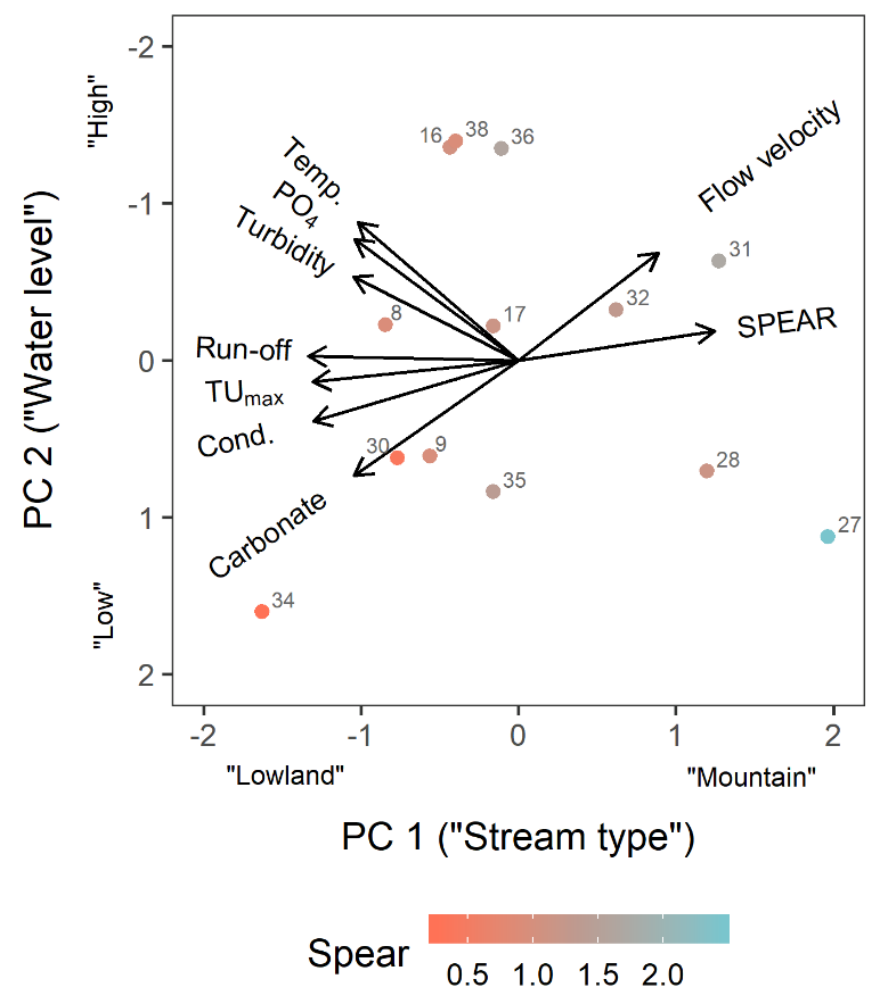

Figure 6: Principal component analysis of the East African SPEAR $\boldsymbol{R}_{\text {pesticides }}$ index and those environmental variables that (marginally) significantly correlated with any of the investigated bioindicators. The first principal component (horizontal axis) explains $60.7 \%$ of the overall variation and was considered to represent a gradient of stream types. The second principal component (vertical axis) additionally explains $14.7 \%$ of the overall variation and was considered to represent a gradient 
of high water level. Each point represents a stream (identified by its number, see Tab. S4 in the

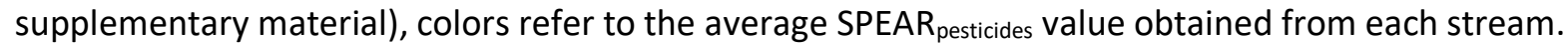

494 Though all these confounding stressors increased simultaneously with the first principal component (considered as stream type), they could be disentangled along the second principal component (Fig. 6): On one end, we observed slow flowing streams with clear water but high conductivity and carbonate hardness. Streams on the other end showed high flow velocity, turbidity and phosphate concentrations, but low conductivity and carbonate hardness. We consider the second principal component to represent a gradient of raised water level at the day of sampling. Raised water levels may have increased flow velocity, as well as turbidity and phosphate levels due to erosion, and decreased conductivity and carbonate levels due to dilution with rainwater. In contrast, neither run-off potential, nor pesticide toxicity $\left(T U_{\max }\right)$ or

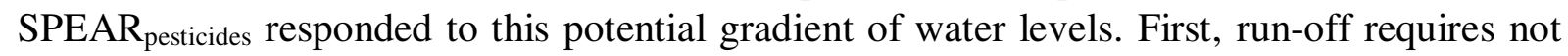
only high water but also nearby agricultural fields. Second, raised water does not mean flooding in this context, which might have been associated with pesticide pollution from run-off (flooded

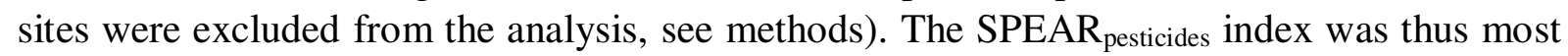
closely associated with pesticide toxicity and run-off potential, indicating indeed a high

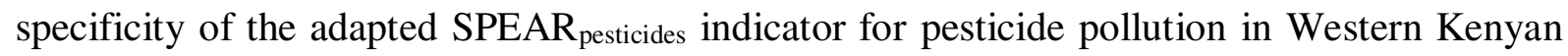
streams. Each of the higher principal components explained only $\leq 8 \%$ of the total variance, and they were thus not further analyzed.

Finally, we compared the performance of SPEAR pesticides in indicating pesticide pollution to those of other bioindicators and commonly applied descriptors of the macroinvertebrate community. Pesticide toxicity most strongly correlated with the East African SPEAR pesticides index $\left(R^{2}=0.53\right)$, followed by the European SPEAR $R_{\text {pesticides }}$ index $\left(R^{2}=0.43\right)$ and the average score per taxon (aspt) of the BMWP indicator $\left(R^{2}=0.33\right.$, Tab. S1). Correlation with the aspt of the SASS5 indicator was lower $\left(R^{2}=0.19\right)$ and not significant. In contrast to SPEAR $R_{\text {pesticides }}$ that was only related to pesticides and their associated stressors (see above), the BMWP and SASS5 indicators were additionally related to phosphate pollution and temperature but did not significantly correspond to run-off potential. The EPT index (cumulative proportion of Ephemeroptera, Plecoptera and Trichoptera) showed a significant but low negative response to pesticide pollution $\left(R^{2}=0.10\right)$, turbidity and carbonate hardness, but increased with flow velocity. The Shannon index for species diversity increased with pesticide pollution, but the response was only marginally significant and may relate to the generally concurrent increase in species richness and pesticide pollution from the spring to more downstream sections (Minshall et al. 1985).

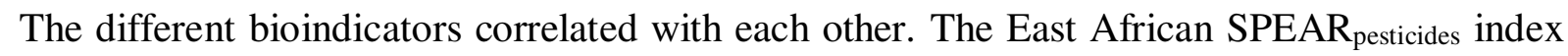
increased with the aspt of the BWMP and SASS5 indicator and with the EPT index, but decreased with species diversity (Tab. S2). BMWP and SASS5 were clearly correlated with each other, but not with the EPT index and species diversity. The EPT index decreased with increasing species diversity.

\section{Discussion}

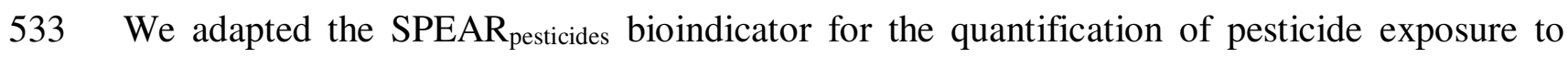
534 afrotropical conditions and demonstrated its use in thirteen Kenyan streams. A detailed step-

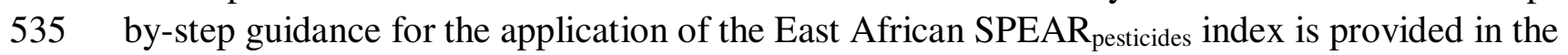


supplementary material. In the following, we discuss the performed modifications of $\mathrm{SPEAR}_{\text {pesticides }}$ and the results from the present case study.

\section{Pesticide pollution in Western Kenya}

539 Pesticides are an important stressor to freshwater macroinvertebrates in small and medium streams of western Kenya. Our results confirm earlier conclusions from various freshwater habitats of the same study area (Kandie et al. (2020); in that study, the chemical freshwater pollution was assessed and the ecological risk ( $\left.\mathrm{TU}_{\text {sum}}\right)$ identified was highest for macroinvertebrates due to insecticide exposure. Pesticide toxicity observed in streams of the present study was comparable to those in European landscapes characterized by intensified agriculture (Becker et al. 2020b). In three out of 13 streams, we observed toxic units exceeding the threshold of $10^{-2}$ that is considered safe according to the first tier of governmental risk assessment in the European Union (EFSA PPR 2013). The results illustrate a need for the monitoring and regulation of pesticide application in order to reduce pesticide exposure in freshwater. In Kenya, plant protection products are sold at relatively low prices without the need for a certificate of competence from retailers, making them widely available to small farmers who are then not informed of the necessary precautions needed to comply to the proposed environmentally safe use. This includes products containing active substances that have been banned in many high income countries, such as the non-selective insecticide diazinon that can be applied on a wide range of crops (https://ec.europa.eu/food/plant/pesticides/eupesticides-database/) and was driving toxicity in most of our sampling sites.

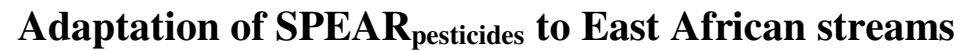

Effects on the macroinvertebrate community composition were successfully quantified even with the non-modified SPEAR pesticides $_{\text {indicator v. } 2019.11 \text { developed for Europe. SPEAR }}$ pesticides values decreased approximately log-linearly with increasing pesticide toxicity when the maximum toxic unit $\left(\mathrm{TU}_{\max }\right)$ ranged from $10^{-4}$ to $10^{-1.5}$. At lower $\mathrm{TU}_{\max }$ values $\mathrm{SPEAR} \mathrm{R}_{\text {pesticides }}$ leveled off, confirming a threshold of $10^{-4}$ to $10^{-3} \mathrm{TU}_{\max }$ below which no effects on freshwater macroinvertebrates have been observed (Schaefer et al. 2012).

Reclassification of the families Coenagrionidae and Corixidae based on toxicity tests with Kenyan species (Becker et al. 2020a) improved the correlation of SPEAR pesticides with $\mathrm{TU}_{\max }$. We suggest determining whether such a reclassification may increase the link between toxicity and invertebrate community composition also in European streams. SPEAR $\mathrm{R}_{\text {pesticides }}$ values from both the European and the adapted East African index were considerably higher in Kenya than those observed in Central European streams (Knillmann et al. 2018), particularly when pesticide toxicity was low. We speculate that in East African streams, the natural proportion of nonvulnerable taxa may be lower. Indeed, macroinvertebrate communities in most Central European streams are dominated by amphipod crustaceans of the genus Gammarus sp., and by mayflies of the Baetis rhodani / vernus group (Becker and Liess 2017). Both groups are considered non-vulnerable to pesticides and often contribute to more than $50 \%$ of individuals. In contrast, amphipod crustaceans were missing in Kenya, confirming previous observations e. g. from Elias et al. (2014). Additionally, we classified mayfly families observed in Kenya as vulnerable (confirmed by a strong decrease with increasing pesticide toxicity, and consistent with most other, less abundant European mayflies). Hence, SPEAR pesticides values in East Africa are associated to higher levels of pesticide toxicity than similar SPEAR pesticides values in Europe, and we adapted the link between the East African SPEAR pesticides $_{\text {index }}$ and $\mathrm{TU}_{\max }$ accordingly. 


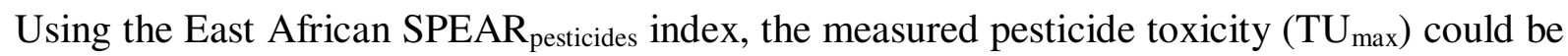
predicted with a precision of 1.3 orders of magnitude in each of the streams. This variation

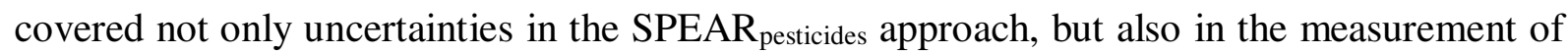
pesticide concentrations and in their conversion to toxic units. Considering the generally high levels of variability and uncertainty in ecotoxicology, as reflected by an assessment factor of 100 ( 2 orders of magnitude) in first tier European risk assessment (EFSA PPR 2013), results

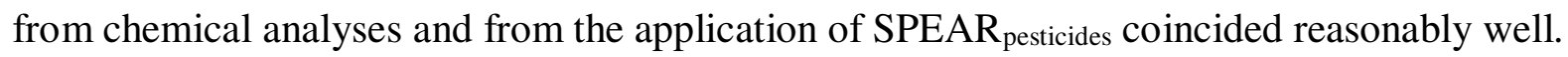

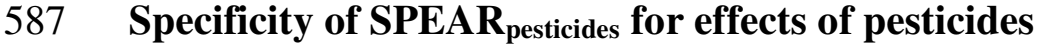

The overall variability in values of the East African SPEAR pesticides index was explained to $53 \%$ by the measured pesticide toxicity, and to $45 \%$ by the estimated run-off potential based on catchment slope and width of buffer strips. The estimated run-off potential was also closely associated with pesticide toxicity and thus provides a fast and simple method for the identification of potential sampling sites of interest, and for the verification of calculated

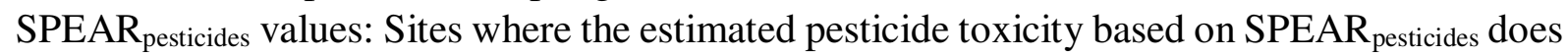
not fit to the estimated run-off potential may be heavily affected by additional stressors and should be investigated further.

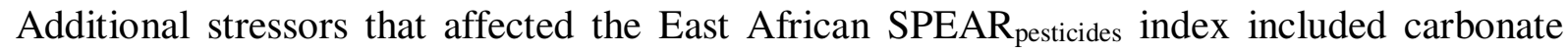
hardness, conductivity and turbidity. All these confounding factors increased with pesticide toxicity along a gradient of different stream types but could be disentangled along a second, independent gradient of increasing water levels. While carbonate hardness, conductivity and turbidity varied with water levels presumably due to erosion and dilution, the SPEAR pesticides index, pesticide pollution and run-off potential did not, because raised water levels alone do not increase run-off without nearby agricultural fields. Thus, our results show that indeed pesticide toxicity and not confounding factors is driving the SPEAR $\mathrm{Resticides}_{\text {index. }}$

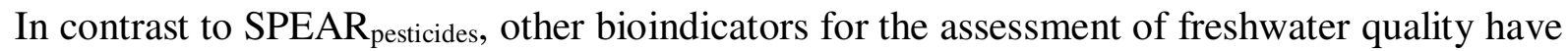
not been designed to specifically indicate effects of pesticides (Dickens and Graham 2002, Paisley et al. 2014). As expected, the BMWP and SASS5 scoring system therefore responded to a broader range of stressors including phosphate and sediment pollution that may be associated with oxygen depletion. Similarly, the EPT index and the Shannon index for species diversity most strongly responded to stressors other than pesticides.

Our application of SPEAR $\mathrm{R}_{\text {pesticides }}$ is not the first attempt to establish or apply bioindicators for the assessment of freshwater quality in East Africa (Masese et al. 2009, Shimba and Jonah 2016, Ochieng et al. 2020). These case studies illustrate the growing interest in the use of bioindicators for freshwater monitoring but did not explicitly consider effects of a specific stressor such as pesticide pollution. Apart from our study, the only application of SPEAR pesticides in sub-Saharan Africa we are aware of has been described in Malherbe et al. (2018). The authors applied a previous version of the European SPEAR pesticides index and the Australian SPEAR $_{\text {pesticides }}$ index (Schaefer et al. 2011a) to macroinvertebrate samples from the Crocodile River and the Harts River in South Africa. The sampling sites were located upstream, adjacent to and downstream of two large irrigation schemes. The SPEAR $\mathrm{R}_{\text {pesticides }}$ index decreased with increasing estimated pesticide toxicity $\left(\mathrm{R}^{2}=0.26\right)$ but the correlation was not significant.

It should be noted that Malherbe et al. (2018) used a very coarse toxicity estimation based on the sampling site location, assuming that pesticide pollution increases from upstream to downstream of the irrigation system. Toxicity estimation thus did not consider pesticide input 
624 from outside the irrigation scheme, whereas our data show that subsistence farming may 625 considerably contribute to pesticide pollution. Therefore, the poor performance of 626 SPEAR $_{\text {pesticides }}$ in Malherbe et al. (2018) may be partly related to uncertainties in the assessment 627 of pesticide exposure. Additionally, the authors sampled macroinvertebrates from large rivers, 628 whereas SPEAR pesticides has been developed for small to medium streams. When we tested the

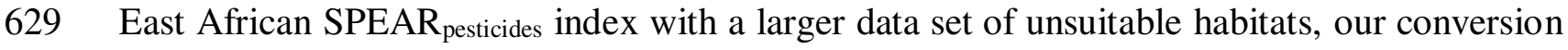

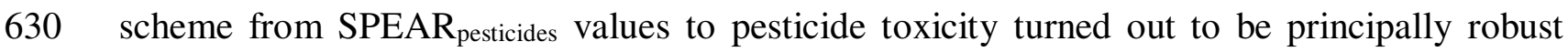
631 despite the small sample size used for development. However, the unexplained variance 632 considerably increased, illustrating the importance to consider that the applicability of 633 SPEAR $_{\text {pesticides }}$ is limited to small and medium streams with flowing water and no heavy 634 streambed degradation (Liess and von der Ohe 2005).

\section{Conclusions}

637 As shown, high impact of pesticides on freshwater organisms is not limited to regions with 638 intensified commercial agriculture. Widespread pesticide pollution in Western Kenyan streams 639 and the associated decline in vulnerable macroinvertebrates indicate an ecological risk also in 640 areas dominated by subsistence farming. Potential negative effects on species diversity and on 641 ecosystem services such as leaf-litter degradation and biological pathogen control illustrate the 642 need to improve the risk management of pesticides also in developing countries. Monitoring is 643 essential in this respect to identify hot spots of pesticide pollution for the targeted development 644 of mitigation measures, and to evaluate the effectiveness of actions that have been taken. We

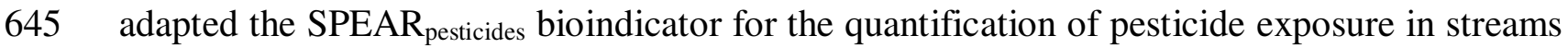
646 of East Africa. This tool provides a cost-efficient alternative to the complex sampling and 647 analysis of chemicals and thus may facilitate large scale monitoring with limited resources in 648 developing countries.

\section{List of abbreviations}

BMWP - Biological Monitoring Working Party index; SASS5 - South African Scoring System

652 5; EPT - Ephemeroptera, Plecoptera \& Trichoptera index; SPEAR pesticides $_{-}$Species at Risk 653 index for pesticides; TU - Toxic Unit

\section{Declarations}

656 Ethics approval and consent to participate

$657 \quad$ N/A

\section{Consent for publication}

659 N/A

660 Availability of data and material

661 All data generated or analysed during this study are included in this published article [and its 662 supplementary information files]. 
This work was supported by the DFG (Deutsche Forschungsgemeinschaft), grant number LI 1708/4-1, BR 2931/3-1, HO 3330/12-1 and the German Helmholtz long-range strategic research funding. We also gratefully acknowledge the financial support for this research by icipe's core donors, Foreign, Commonwealth \& Development Office (FCDO) of the UK Government; Swedish International Development Cooperation Agency (Sida); the Swiss Agency for Development and Cooperation (SDC); Federal Democratic Republic of Ethiopia; and the Kenyan Government.

\section{Authors' contributions}

ML conceived the approach; AG, FK, UF, FM, BT, WB, ML, HH \& JB designed the research; AG, FK and JB conducted the research; JB and AG analysed and interpreted the data; JB and AG drafted the initial version; AG, FK, UF, FM, BT, WB, ML \& JB contributed to the final version - all approved the final version of the publication.

AG: Akbar A. Ganatra; FK: Faith Jebiwot Kandie; UF: Ulrike Fillinger; FM: Francis McOdimba; BT: Baldwyn Torto; WB: Werner Brack; ML: Matthias Liess; HH: Henner Hollert; JB: Jeremias Becker

Acknowledgements:

We would like to thank the technical staff at icipe-TOC specifically Paul Ouma and William Owigo for their help during data collection. We would like to thank the developers of the free software statistical program R. All maps in were created using ArcGIS® software by Esri. ArcGIS ${ }^{\circledR}$ and ArcMap ${ }^{\mathrm{TM}}$ are the intellectual property of Esri and are used herein under license. Copyright (C) Esri. All rights reserved. For more information about Esri® software, please visit www.esri.com.'

687 The author(s) declare no competing interests.

688

689

690

\section{1}

\section{Competing interests}

\section{Authors' information (optional)}

N/A

\section{References}

Becker JM, Ganatra AA, Kandie F, Mühlbauer L, Ahlheim J, Brack W, Torto B, Agola EL, McOdimba F, Hollert H, Fillinger U, Liess M (2020a) Pesticide pollution in freshwater paves the way for schistosomiasis transmission. Scientific Reports 10(1): 3650. doi: 10.1038/s41598020-60654-7.

Becker JM, Liess M (2017) Species Diversity Hinders Adaptation to Toxicants. Environ Sci Technol 51(17): 10195-10202. doi: 10.1021/acs.est.7b02440.

Becker JM, Russo R, Shahid N, Liess M (2020b) Drivers of pesticide resistance in freshwater amphipods. Sci Total Environ 735: $139264 . \quad$ doi: https://doi.org/10.1016/j.scitotenv.2020.139264.

Beketov MA, Foit K, Schaefer RB, Schriever CA, Sacchi A, Capri E, Biggs J, Wells C, Liess M (2009) SPEAR indicates pesticide effects in streams - Comparative use of species- and 
Beketov MA, Kefford BJ, Schaefer RB, Liess M (2013) Pesticides reduce regional biodiversity

706 of stream invertebrates. Proc Natl Acad Sci USA 110(27): 11039-11043. doi: 10.1073/pnas.1305618110. Beketov MA, Schäfer RB, Marwitz A, Paschke A, Liess M (2008) Long-term stream invertebrate community alterations induced by the insecticide thiacloprid: effect concentrations and recovery dynamics. Sci Total Environ 405(1-3): 96-108. doi: 10.1016/j.scitotenv.2008.07.001.

Bere T, Nyamupingidza BB (2014) Use of biological monitoring tools beyond their country of origin: a case study of the South African Scoring System Version 5 (SASS5). Hydrobiologia 722(1): 223-232. doi: 10.1007/s10750-013-1702-7.

Brock TCM, Van Wijngaarden RPA (2012) Acute toxicity tests with Daphnia magna, Americamysis bahia, Chironomus riparius and Gammarus pulex and implications of new EU requirements for the aquatic effect assessment of insecticides. Environ Sci Pollut Res 19(8): 3610-3618. doi: 10.1007/s11356-012-0930-0.

Cold A, Forbes VE (2004) Consequences of a short pulse of pesticide exposure for survival and reproduction of Gammarus pulex. Aquat Toxicol 67(3): 287-299. doi: 10.1016/j.aquatox.2004.01.015.

Dickens CW, Graham PM (2002) The South African Scoring System (SASS) Version 5 Rapid Bioassessment Method for Rivers. African Journal of Aquatic Science 27(1): 1-10. doi: 10.2989/16085914.2002.9626569.

ECOTOXicology Knowledgebase (2019) U.S. Environmental Protection Agency (USEPA), Office of Pesticide Programs, Environmental Fate and Effects Division, Ecological Effects Branch.

http://cfpub.epa.gov/ecotox/help.cfm?help id=DATASTEWARD\&help type=define\&help b ack=1. Accessed 2019-03-26.

EFSA PPR (2013) Guidance on tiered risk assessment for plant protection products for aquatic organisms in edge-of-field surface waters. EFSA Journal 11(7): 3290. doi: 10.2903/j.efsa.2013.3290.

Elias J, Ijumba J, Mgaya Y, Mamboya F (2014) Study on Freshwater Macroinvertebrates of Some Tanzanian Rivers as a Basis for Developing Biomonitoring Index for Assessing Pollution in Tropical African Regions. Journal of Ecosystems 2014: 1-8. doi: 10.1155/2014/985389.

Geiger F, Bengtsson J, Berendse F, Weisser WW, Emmerson M, Morales MB, Ceryngier P, Liira J, Tscharntke T, Winqvist C, Eggers S, Bommarco R, Pärt T, Bretagnolle V, Plantegenest M, Clement LW, Dennis C, Palmer C, Oñate JJ, Guerrero I, Hawro V, Aavik T, Thies C, Flohre A, Hänke S, Fischer C, Goedhart PW, Inchausti P (2010) Persistent negative effects of pesticides on biodiversity and biological control potential on European farmland. Basic Appl Ecol 11(2): 97-105. doi: https://doi.org/10.1016/j.baae.2009.12.001.

Hunt L, Bonetto C, Marrochi N, Scalise A, Fanelli S, Liess M, Lydy MJ, Chiu MC, Resh VH (2017) Species at Risk (SPEAR) index indicates effects of insecticides on stream invertebrate communities in soy production regions of the Argentine Pampas. Sci Total Environ 580: 699709. doi: https://doi.org/10.1016/j.scitotenv.2016.12.016.

Kandie FJ, Krauss M, Beckers L-M, Massei R, Fillinger U, Becker J, Liess M, Torto B, Brack $\mathrm{W}$ (2020) Occurrence and risk assessment of organic micropollutants in freshwater systems within the Lake Victoria South Basin, Kenya. Sci Total Environ 714: 136748. doi: https://doi.org/10.1016/j.scitotenv.2020.136748.

Knillmann S, Orlinskiy P, Kaske O, Foit K, Liess M (2018) Indication of pesticide effects and recolonization in streams. Sci Total Environ 630: 1619-1627. doi: https://doi.org/10.1016/j.scitotenv.2018.02.056. 
Kreuger J (1998) Pesticides in stream water within an agricultural catchment in southern Sweden, 1990-1996. Sci Total Environ 216(3): 227-251. doi: https://doi.org/10.1016/S00489697(98)00155-7.

756 Liess M, Schafer RB, Schriever CA (2008) The footprint of pesticide stress in communities species traits reveal community effects of toxicants. Sci Total Environ 406(3): 484-490. doi: 10.1016/j.scitotenv.2008.05.054.

Liess M, Schulz R (1999) Linking insecticide contamination and population response in an agricultural stream. Environ Toxicol Chem 18(9): 1948-1955. doi: 10.1002/etc.5620180913. Liess M, Schulz R, Liess MHD, Rother B, Kreuzig R (1999) Determination of insecticide contamination in agricultural headwater streams. Water Research 33(1): 239-247. doi: 10.1016/s0043-1354(98)00174-2.

Liess M, von der Ohe PC (2005) Analyzing effects of pesticides on invertebrate communities in streams. Environ Toxicol Chem 24(4): 954-965. doi: 10.1897/03-652.1.

766 Malherbe W, van Vuren JHJ, Wepener V (2018) The Application of a Macroinvertebrate

767

768

769

770

771

772

773

774

775

776

777

778

779

780

781

782

783

784

785

786

787

788

789

790

791

792

793

794

795

796

797

798

799

800

801 Indicator in Afrotropical Regions for Pesticide Pollution. J Toxicol 2018: 2581930-2581930. doi: 10.1155/2018/2581930.

Masese FO, Raburu PO, Muchiri M (2009) A preliminary benthic macroinvertebrate index of biotic integrity (B-IBI) for monitoring the Moiben River, Lake Victoria Basin, Kenya. African Journal of Aquatic Science 34(1): 1-14. doi: 10.2989/AJAS.2009.34.1.1.726.

Menezes S, Baird DJ, Soares AMVM (2010) Beyond taxonomy: a review of macroinvertebrate trait-based community descriptors as tools for freshwater biomonitoring. J Appl Ecol 47(4): 711-719. doi: https://doi.org/10.1111/j.1365-2664.2010.01819.x.

Minshall GW, Petersen RC, Nimz CF (1985) Species Richness in Streams of Different Size from the Same Drainage Basin. Am Nat 125(1): 16-38. doi: 10.1086/284326.

Morrissey CA, Mineau P, Devries JH, Sanchez-Bayo F, Liess M, Cavallaro MC, Liber K (2015) Neonicotinoid contamination of global surface waters and associated risk to aquatic invertebrates: A review. Environment International 74: 291-303. doi: https://doi.org/10.1016/j.envint.2014.10.024.

Münze R, Hannemann C, Orlinskiy P, Gunold R, Paschke A, Foit K, Becker JM, Kaske O, Paulsson E, Peterson M, Jernstedt H, Kreuger J, Schüürmann G, Liess M (2017) Pesticides from wastewater treatment plant effluents affect invertebrate communities. Sci Total Environ 599-600: 387-399. doi: doi.org/10.1016/j.scitotenv.2017.03.008.

Münze R, Orlinskiy P, Gunold R, Paschke A, Kaske O, Beketov MA, Hundt M, Bauer C, Schüürmann G, Möder M, Liess M (2015) Pesticide impact on aquatic invertebrates identified with Chemcatcher® passive samplers and the SPEARpesticides index. Sci Total Environ 537: 69-80. doi: 10.1016/j.scitotenv.2015.07.012.

Ochieng H, Odong R, Okot-Okumu J (2020) Comparison of temperate and tropical versions of Biological Monitoring Working Party (BMWP) index for assessing water quality of River Aturukuku in Eastern Uganda. Global Ecology and Conservation 23: e01183. doi: https://doi.org/10.1016/j.gecco.2020.e01183.

Paisley MF, Trigg DJ, Walley WJ (2014) Revision of the Biological Monitoring Working Party (BMWP) Score System: Derivation of Present-Only and Abundance-Related Scores from Field Data. River Research and Applications 30(7): 887-904. doi: 10.1002/rra.2686.

PPDB - The Pesticide Properties Database (2019) Agriculture \& Environment Research Unit AERU, University of Hertfordshire. http://sitem.herts.ac.uk/aeru/iupac/index.htm. Accessed 2019-03-26.

Reiber L, Knillmann S, Foit K, Liess M (2020) Species occurrence relates to pesticide gradient in streams. Sci Total Environ 735: 138807. doi: https://doi.org/10.1016/j.scitotenv.2020.138807. 
802 Roubos CR, Rodriguez-Saona C, Isaacs R (2014) Mitigating the effects of insecticides on 803 arthropod biological control at field and landscape scales. Biol Control 75: 28-38. doi: 804 https://doi.org/10.1016/j.biocontrol.2014.01.006.

805 Rundlöf M, Andersson GKS, Bommarco R, Fries I, Hederström V, Herbertsson L, Jonsson O, 806 Klatt BK, Pedersen TR, Yourstone J, Smith HG (2015) Seed coating with a neonicotinoid insecticide negatively affects wild bees. Nature 521(7550): 77-80. doi: 10.1038/nature14420. Sánchez-Bayo F, Wyckhuys KAG (2019) Worldwide decline of the entomofauna: A review of its drivers. Biological Conservation 232: 8-27. doi: https://doi.org/10.1016/j.biocon.2019.01.020.

811 Schaefer RB, Kefford BJ, Metzeling L, Liess M, Burgert S, Marchant R, Pettigrove V, Goonan 812 P, Nugegoda D (2011a) A trait database of stream invertebrates for the ecological risk 813 assessment of single and combined effects of salinity and pesticides in South-East Australia. 814 Sci Total Environ 409(11): 2055-2063. doi: 10.1016/j.scitotenv.2011.01.053.

815 Schaefer RB, Van den Brink PJ, Liess M (2011b). Impacts of pesticides on freshwater 816 ecosystems. In: Ecological impacts of toxic chemicals. F. Sánchez-Bayo, P. J. Van den Brink and R. M. Mann. Bentham Science Publishers Ltd.: 111-137.

Schaefer RB, von der Ohe PC, Rasmussen J, Kefford BJ, Beketov MA, Schulz R, Liess M (2012) Thresholds for the Effects of Pesticides on Invertebrate Communities and Leaf Breakdown in Stream Ecosystems. Environ Sci Technol 46(9): 5134-5142. doi: 10.1021/es2039882.

Schäfer RB, Paschke A, Vrana B, Mueller R, Liess M (2008) Performance of the Chemcatcher ${ }^{\circledR}$ passive sampler when used to monitor 10 polar and semi-polar pesticides in 16 Central European streams, and comparison with two other sampling methods. Water Research 42(10): 2707-2717. doi: 10.1016/j.watres.2008.01.023.

Schriever CA, von der Ohe PC, Liess M (2007) Estimating pesticide runoff in small streams. Chemosphere 68(11): 2161-2171. doi: 10.1016/j.chemosphere.2007.01.086.

Sharma A, Kumar V, Shahzad B, Tanveer M, Sidhu GPS, Handa N, Kohli SK, Yadav P, Bali AS, Parihar RD, Dar OI, Singh K, Jasrotia S, Bakshi P, Ramakrishnan M, Kumar S, Bhardwaj R, Thukral AK (2019) Worldwide pesticide usage and its impacts on ecosystem. SN Applied Sciences 1(11): 1446. doi: 10.1007/s42452-019-1485-1.

Shimba MJ, Jonah FE (2016) Macroinvertebrates as bioindicators of water quality in the Mkondoa River, Tanzania, in an agricultural area. African Journal of Aquatic Science 41(4): 453-461. doi: 10.2989/16085914.2016.1230536.

Sprague JB (1970) Measurement of pollutant toxicity to fish. II. Utilizing and applying bioassay results. Water Research 4(1): 3-32. doi: 10.1016/0043-1354(70)90018-7.

Talebi K, Kavousi A, Sabahi Q (2008) Impacts of Pesticides on Arthropod Biological Control Agents. Pest Technology 2(2): 87-97.

Van Dijk T, Van Staalduinen M, Van der Sluijs J (2013) Macro-Invertebrate Decline in Surface Water Polluted with Imidacloprid. PLoS ONE 8(5). doi: 10.1371/journal.pone.0062374.

Von Der Ohe PC, Liess M (2004) Relative sensitivity distribution of aquatic invertebrates to organic and metal compounds. Environ Toxicol Chem 23(1): 150-156. doi: 10.1897/02-577.

Wambugu PW, Muthamia ZK (2009): Country Report on the State of Plant Genetic Resources for Food and Agriculture. Kenya Agricultural Research Institute, National Genebank of Kenya. Nairobi, Kenya.

Wang Z, Kwok KWH, Lui GCS, Zhou G-J, Lee J-S, Lam MHW, Leung KMY (2014) The difference between temperate and tropical saltwater species' acute sensitivity to chemicals is relatively small. Chemosphere 105: 31-43. doi: 10.1016/j.chemosphere.2013.10.066.

Williams RJ, Brooke DN, Matthiessen P, Mills M, Turnbull A, Harrison RM (1995) Pesticide Transport to Surface Waters within an Agricultural Catchment. Water and Environment Journal 9(1): 72-81. doi: 10.1111/j.1747-6593.1995.tb00928.x. 


\section{Figures}

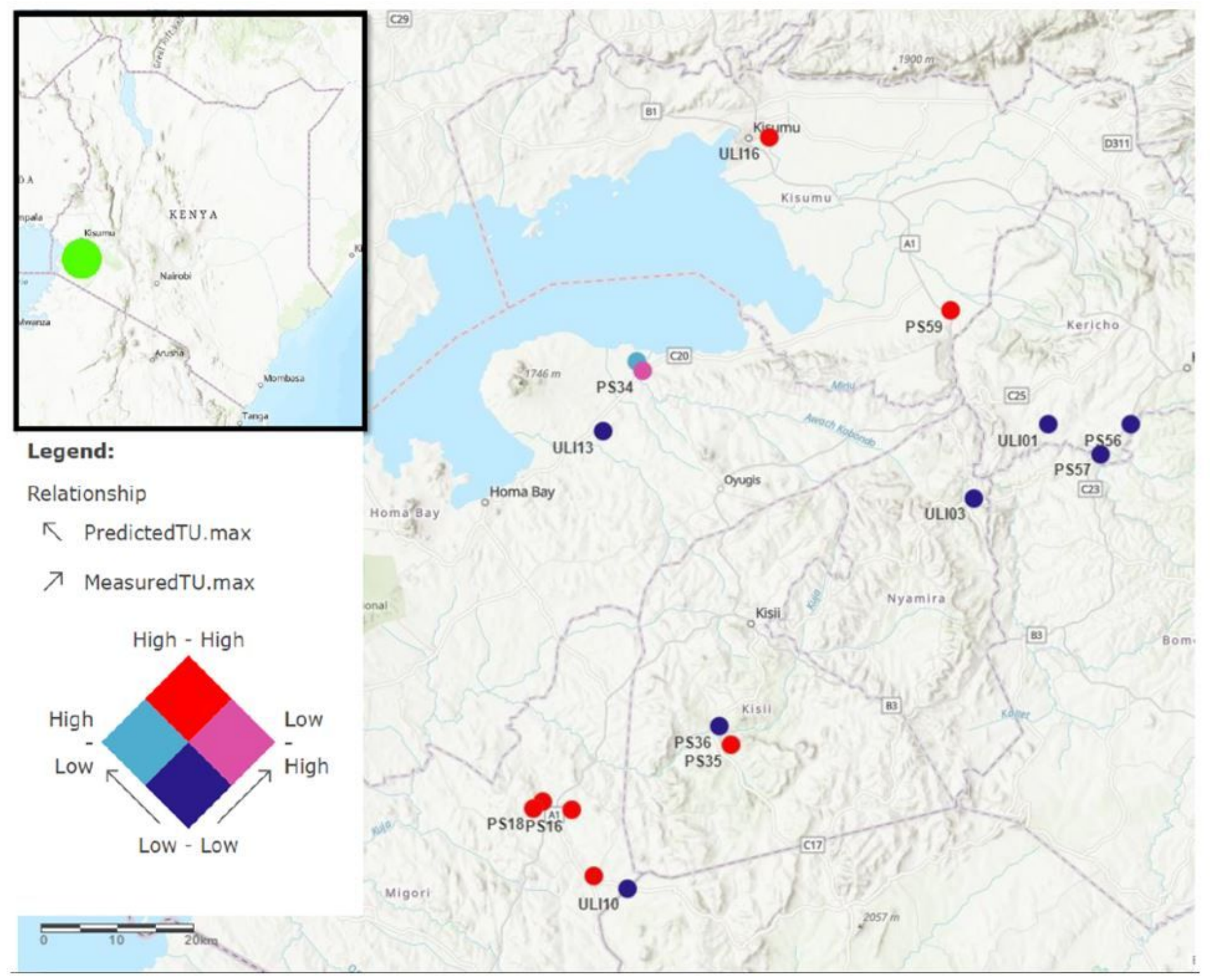

\section{Figure 1}

Location of the sampling sites in the study area of Western Kenya, East Africa. Site locations are displayed with the site code and colour-filled to annotate the relationship between predicted pesticide pollution (TUmax) using SPEARpesticides and measured pollution in water samples using LC-HRMS in Kandie et al. (2020). Akbar Ganatra. "SPEARpesticides study sites". "World Topographical map" \& "World Hillshade". February 2nd, 2021. https://arcg.is/1fiDn9. 


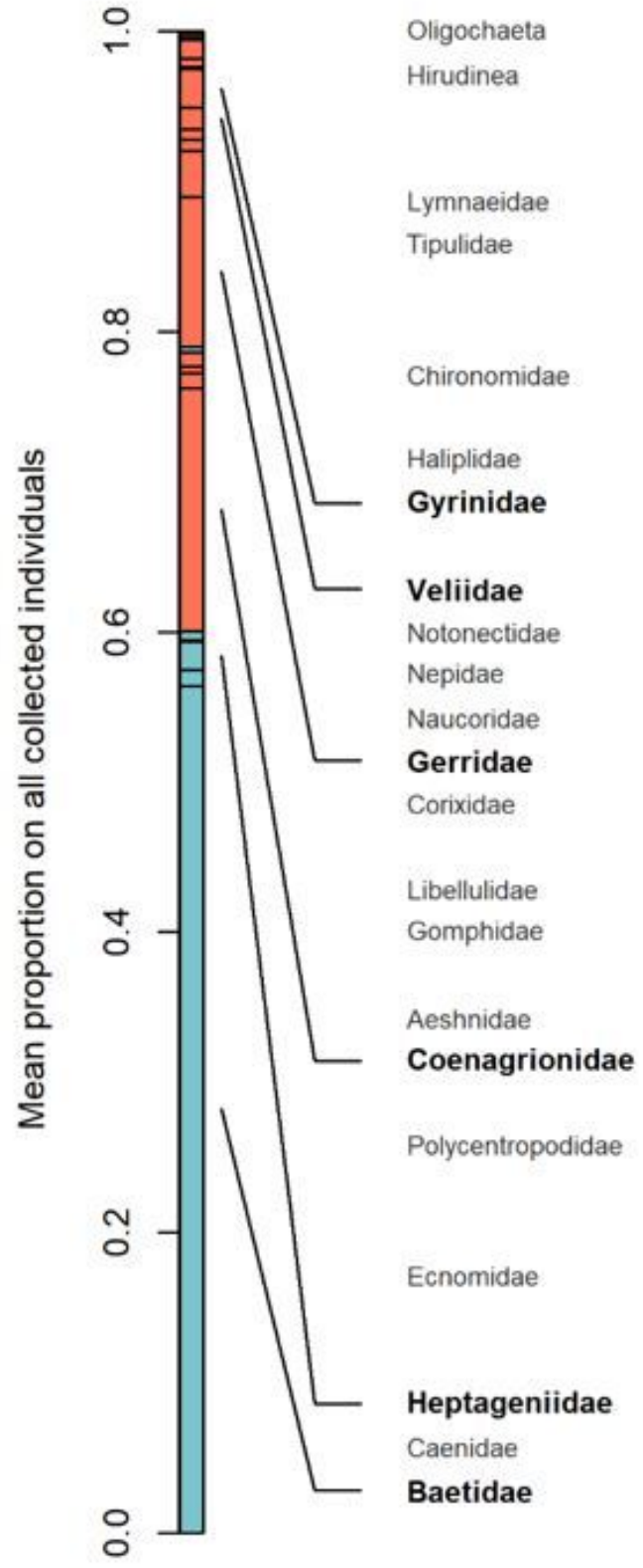

Lowly polluted streams

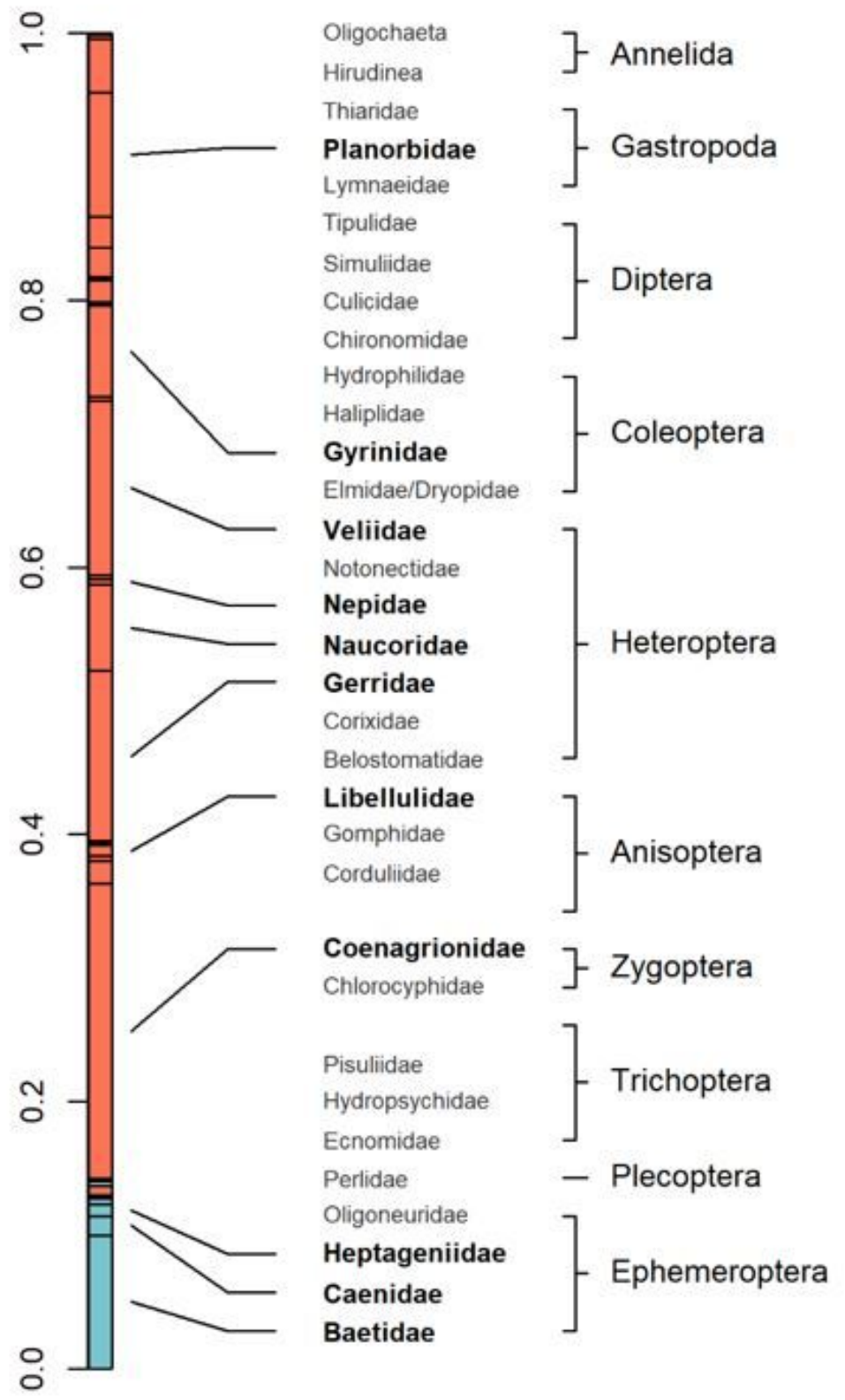

Highly polluted streams

\section{Figure 2}

The freshwater macroinvertebrate community composition changes in streams with high pesticide pollution. The stacked bars show the mean proportions of macroinvertebrate families on the overall number of individuals observed in lowly-polluted (maximum toxic unit TUmax $<10-3$ ) and in highly polluted streams (TUmax $\geq 10-3$ ). The number of individuals ranged from 32 to 154 (mean: 94) in the 5 lowly polluted streams and from 37 to 462 (mean: 152) in the 8 highly polluted streams. Families that were recorded in at least $50 \%$ of the streams are shown in in bold. Taxa shown in blue have been classified as being at risk in the adapted SPEARpesticides indicator for East African streams, taxa shown in red have been classified not at risk. 
(a)

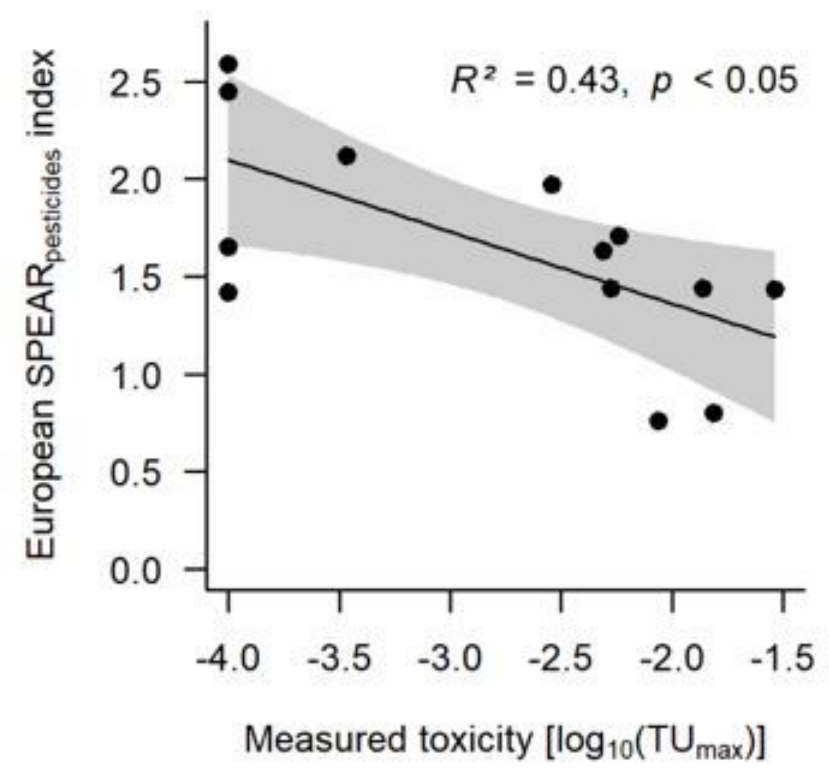

(b)

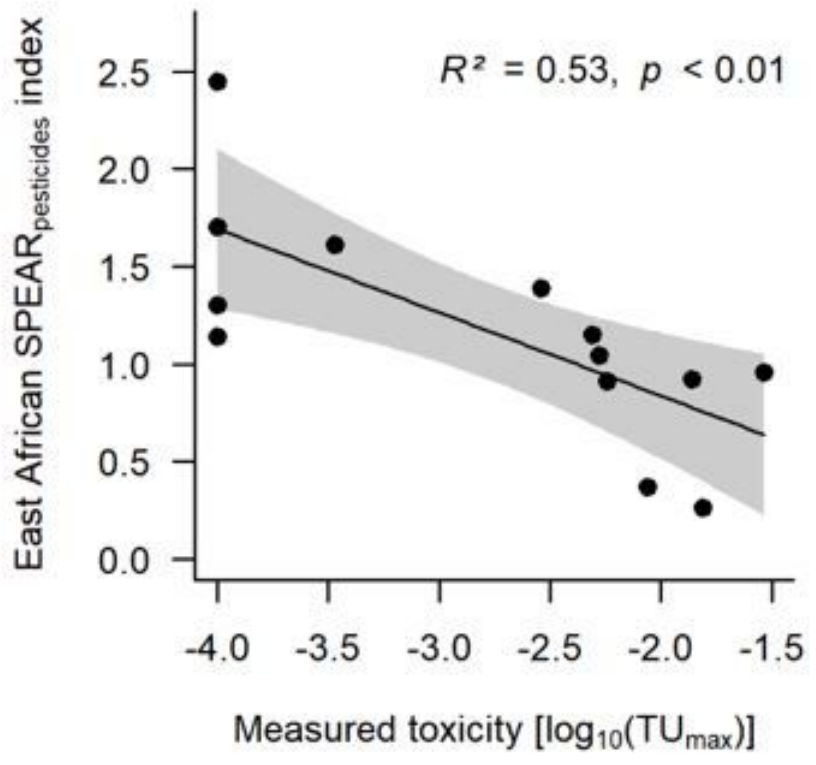

\section{Figure 3}

SPEARpesticides indicates pesticide pollution in tropical streams of Western Kenya. Pesticide pollution was quantified as the maximum toxic unit (TUmax, restricted to $\geq 10-4$ ) out of 30 pesticides measured in water samples collected during the rainy season but not during peak exposure. Freshwater macroinvertebrates were identified to the family level. (a) Application of the European SPEARpesticides index v. 2019.11 from Knillmann et al. (2018) to the Kenyan samples; $R^{2}=0.43, F=8.15$, $d f=1$, res. $d f=$ $11, p=0.016$, intercept $=0.62$, slope $=-0.37$. (b) Application of the SPEARpesticides index after adaption to East African streams. $R^{2}=0.53, F=12.35, d f=1$, res. $d f=11, p=0.005$, intercept $=-0.02$, slope $=-0.43$. 
(a)

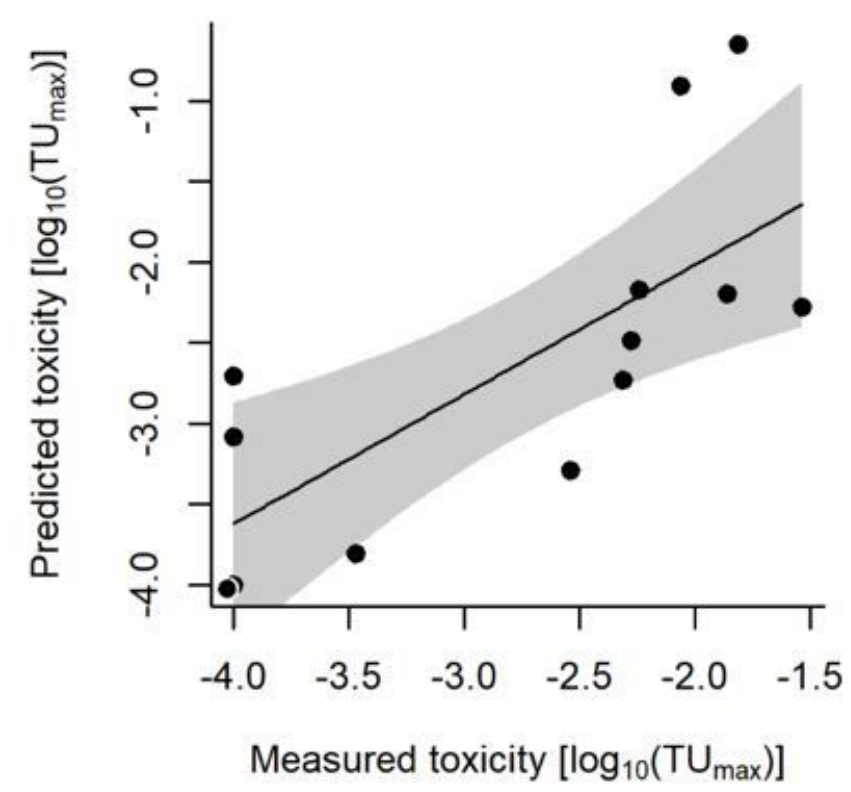

(b)

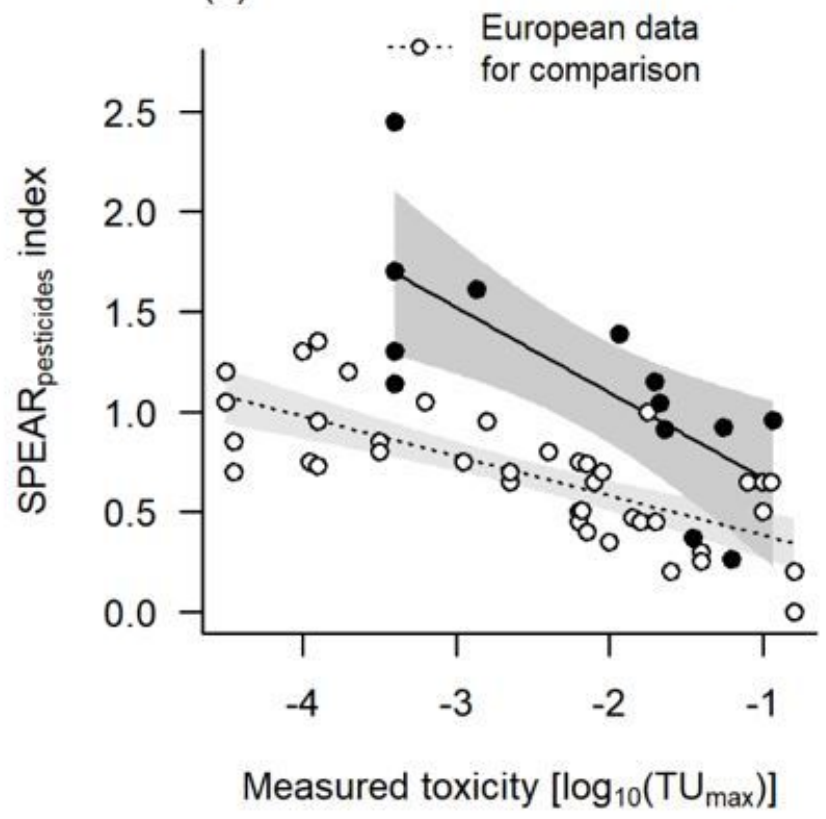

Figure 4

Performance of the East African SPEARpesticides index. (a) Background pesticide toxicity (maximum toxic unit, TUmax) predicted with the East African SPEARpesticides index correlates with the measured background toxicity in Kenyan water samples. $\mathrm{R}^{2}=0.54, \mathrm{~F}=12.97$, $\mathrm{df}=1$, res. $\mathrm{df}=11, \mathrm{p}=0.004$, intercept $=-0.41$, slope $=0.80$. TUmax was restricted to $\geq 10-4$, because lower toxicity could not be measured due to detection limits for pesticides. TUmax has been log10-transformed, so that differences are presented in orders of magnitude. (b) Relation of the East African SPEARpesticides index with the estimated peak pesticide toxicity during run-off in Kenyan streams, as compared to the relation of the European SPEARpesticides index v. 219.11 with measured peak toxicity in German streams (data from Knillmann et al. 2018). Peak exposure in Kenyan streams was estimated by multiplying the measured background toxicity with a correction factor of 4 (see main text for justification). 

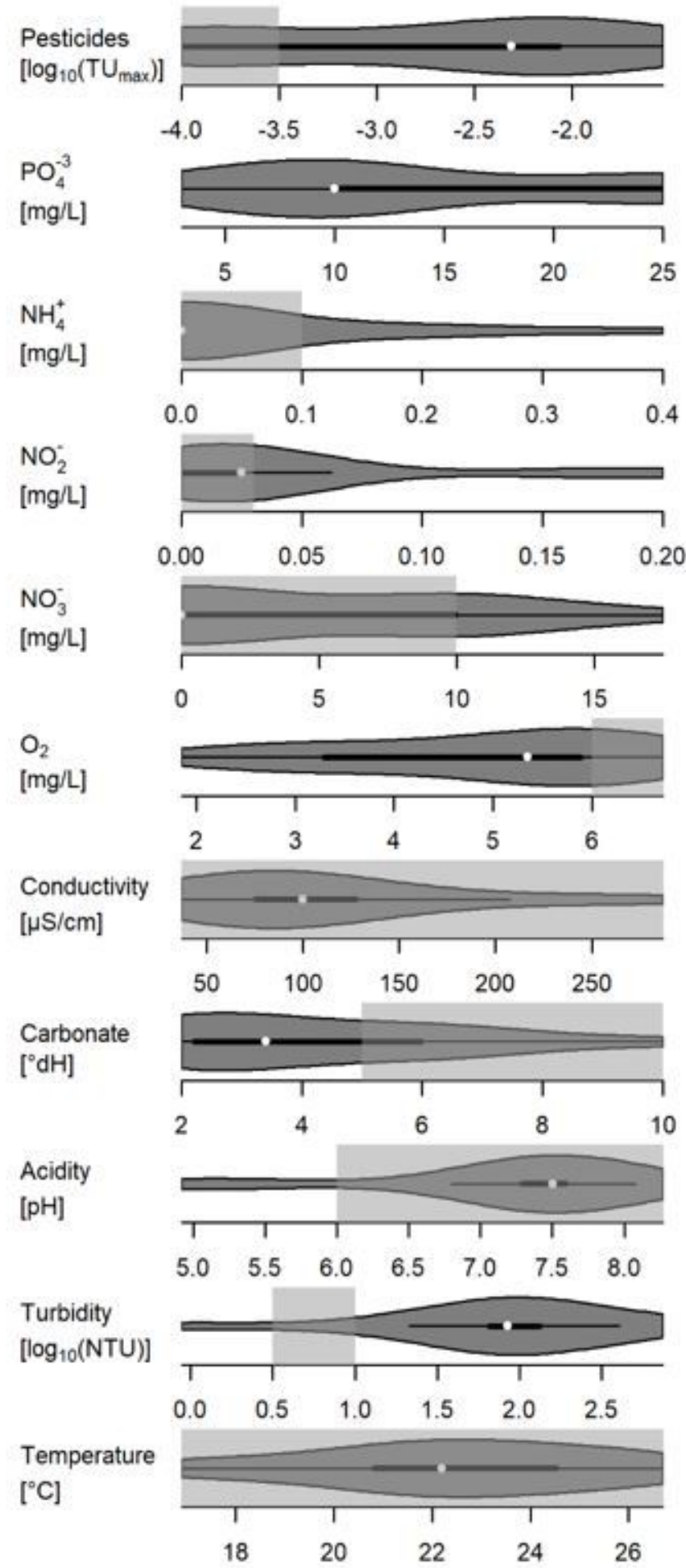

\section{Figure 5}

Distribution of physicochemical parameter values at the study sites. The violin plot shows the kernel probability density of the data points across the parameter values. White points indicate the median, black boxes the interquartile range, and black lines $1.5 \mathrm{x}$ the interquartile range. Light-grey boxes indicate the range of values considered typical or recommend for streams with good water quality. 

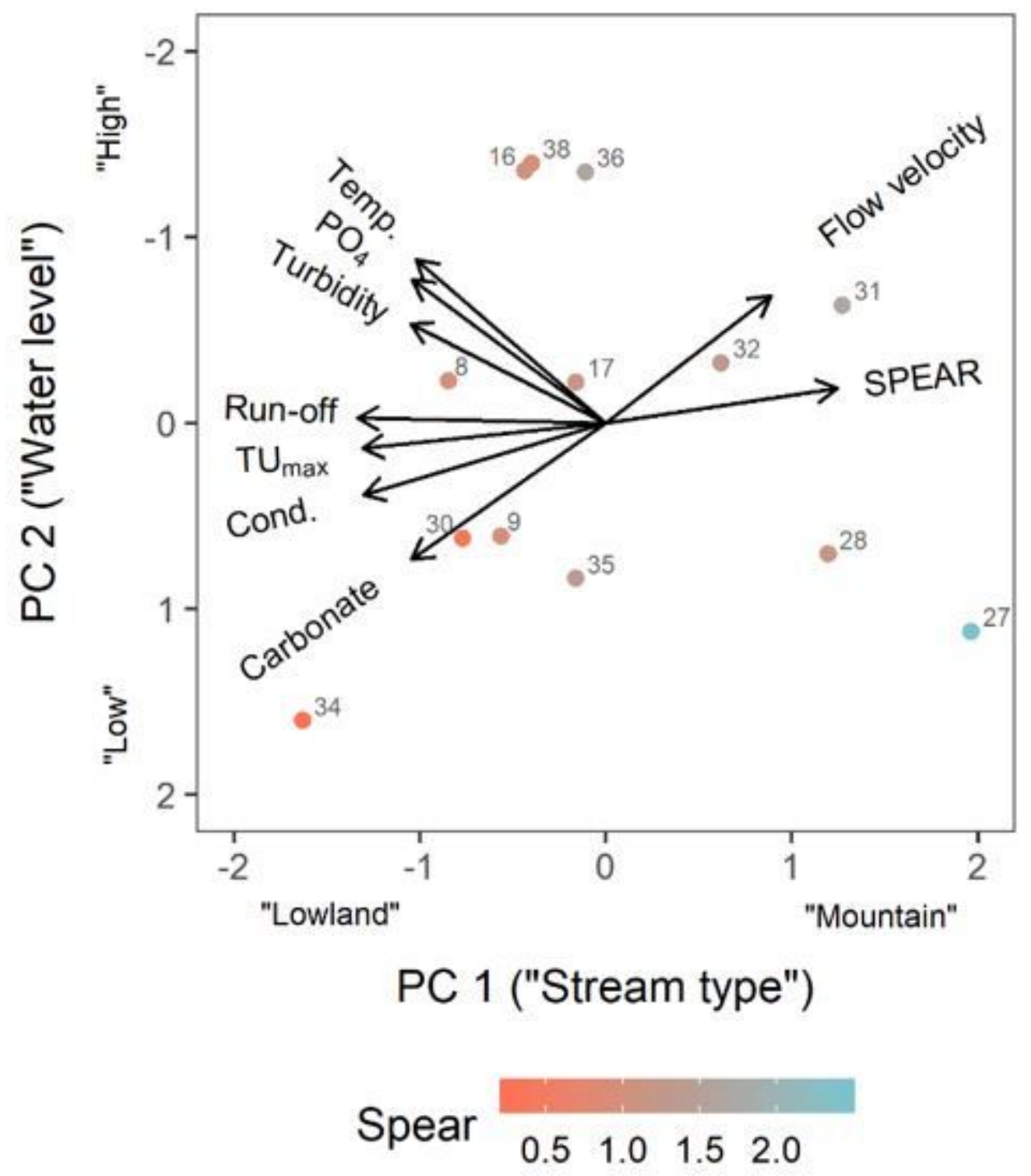

\section{Figure 6}

Principal component analysis of the East African SPEARpesticides index and those environmental variables that (marginally) significantly correlated with any of the investigated bioindicators. The first principal component (horizontal axis) explains $60.7 \%$ of the overall variation and was considered to represent a gradient of stream types. The second principal component (vertical axis) additionally explains $14.7 \%$ of the overall variation and was considered to represent a gradient of high water level. Each point represents a stream (identified by its number, see Tab. S4 in the supplementary material), colors refer to the average SPEARpesticides value obtained from each stream.

\section{Supplementary Files}

This is a list of supplementary files associated with this preprint. Click to download.

- aGanatra2021Supplementaryinformationrawdata.xlsx 
- aGanatra2021Supplementaryinformation.docx 